Article

\title{
Attributional \& Consequential Life Cycle Assessment: Definitions, Conceptual Characteristics and Modelling Restrictions
}

\author{
Thomas Schaubroeck ${ }^{1, *(\mathbb{D}}$, Simon Schaubroeck ${ }^{2,3}{ }^{\text {, Reinout Heijungs }}{ }^{4,5}{ }^{\infty}$, Alessandra Zamagni ${ }^{6}$, \\ Miguel Brandão ${ }^{7}\left[\right.$ and Enrico Benetto ${ }^{1}$ \\ 1 Luxembourg Institute of Science and Technology, 5 Avenue des Hauts-Fourneaux, Esch-sur-Alzette, \\ 4362 Luxembourg, Luxembourg; enrico.benetto@list.lu \\ 2 Suda Limited, Hong Kong, China; simon.schaubroeck@gmail.com or simon.schaubroeck@kuleuven.be \\ 3 Department of Architecture, Faculty of Engineering Science, KU Leuven, Kasteelpark Arenberg 1-Box 2431, \\ 3001 Leuven, Belgium \\ 4 Institute of Environmental Sciences (CML), Leiden University, Einsteinweg 2, 2333 CC Leiden, The Netherlands; \\ Heijungs@cml.leidenuniv.nl \\ 5 Department of Operations Analytics, Vrije Universiteit Amsterdam, De Boelelaan 1105, \\ 1081 HV Amsterdam, The Netherlands \\ 6 Ecoinnovazione srl spin-off ENEA, Via Ferrarese 3, 40128 Bologna, Italy; a.zamagni@ecoinnovazione.it \\ 7 Division of Sustainability Assessment and Management, Department of Sustainable Development, \\ Environmental Science and Engineering, School of Architecture and the Built Environment, KTH-Royal \\ Institute of Technology, 10044 Stockholm, Sweden; miguelb@kth.se \\ * Correspondence: thomas.schaubroeck@list.lu
}

\section{check for} updates

Citation: Schaubroeck, T.; Schaubroeck, S.; Heijungs, R.; Zamagni, A.; Brandão, M.; Benetto, E. Attributional \& Consequential Life Cycle Assessment: Definitions, Conceptual Characteristics and Modelling Restrictions. Sustainability 2021, 13, 7386. https://doi.org/ $10.3390 /$ su13137386

Academic Editors: Alan Randall and Marc A. Rosen

Received: 26 March 2021

Accepted: 29 June 2021

Published: 1 July 2021

Publisher's Note: MDPI stays neutral with regard to jurisdictional claims in published maps and institutional affiliations.

Copyright: (c) 2021 by the authors. Licensee MDPI, Basel, Switzerland. This article is an open access article distributed under the terms and conditions of the Creative Commons Attribution (CC BY) license (https:// creativecommons.org/licenses/by/ $4.0 /)$.
Abstract: To assess the potential environmental impact of human/industrial systems, life cycle assessment (LCA) is a very common method. There are two prominent types of LCA, namely attributional (ALCA) and consequential (CLCA). A lot of literature covers these approaches, but a general consensus on what they represent and an overview of all their differences seems lacking, nor has every prominent feature been fully explored. The two main objectives of this article are: (1) to argue for and select definitions for each concept and (2) specify all conceptual characteristics (including translation into modelling restrictions), re-evaluating and going beyond findings in the state of the art. For the first objective, mainly because the validity of interpretation of a term is also a matter of consensus, we argue the selection of definitions present in the 2011 UNEP-SETAC report. ALCA attributes a share of the potential environmental impact of the world to a product life cycle, while CLCA assesses the environmental consequences of a decision (e.g., increase of product demand). Regarding the second objective, the product system in ALCA constitutes all processes that are linked by physical, energy flows or services. Because of the requirement of additivity for ALCA, a double-counting check needs to be executed, modelling is restricted (e.g., guaranteed through linearity) and partitioning of multifunctional processes is systematically needed (for evaluation per single product). The latter matters also hold in a similar manner for the impact assessment, which is commonly overlooked. CLCA, is completely consequential and there is no limitation regarding what a modelling framework should entail, with the coverage of co-products through substitution being just one approach and not the only one (e.g., additional consumption is possible). Both ALCA and CLCA can be considered over any time span (past, present \& future) and either using a reference environment or different scenarios. Furthermore, both ALCA and CLCA could be specific for average or marginal (small) products or decisions, and further datasets. These findings also hold for life cycle sustainability assessment.

Keywords: multifunctionality; system boundary; ISO; life cycle inventory; attributional; consequential; functional unit; product system; temporal; life cycle impact assessment 


\section{Introduction}

Increasing concerns over the impact of human activities have led to a growing interest to assess the environmental impact of product systems. A common and recommended method to estimate environmental impacts comprehensively and systematically is life cycle assessment (LCA), which focuses on the environmental impact from a life cycle perspective, e.g., covering possibly also disposal of products and other relevant life cycle phases [1,2]. A multitude of scientific publications have covered the difference between various types of LCA, of which a summary is presented by Guinée et al. [3]. A particular prominent subject of debate is the difference between attributional LCA (ALCA) and consequential LCA (CLCA). These types will be explained further on in the text as part of our study. Other types of LCA have been postulated [3], but none of them seem to have received as much attention as these two and had an as profound impact on the LCA field in general, from theory to application, in our opinion. Moreover, the specification of these concepts has already started in 1993, with the specific terminology being brought forward in 2001, and the number of papers at least explicitly addressing consequential LCA have continuously increased to about 40 per year in 2018 [4].

The goal of this study is to specify the concepts of ALCA and CLCA, covering a set of conceptual characteristics, and specify related imposed modelling restrictions, this in an objective manner. Moreover, the focus of this article is not directly on associated modelling frameworks and not at all on applications. In light of this, a distinction needs to be made between concept, modelling framework and application (See Figure 1). These are general notions belonging to any field, and we illustrate this general nature using the example of natural system in Figure 1. Specification in the context of LCA is done in Section 2. Coming back on the notions, the concept behind an assessment may be the coverage of a certain effect (e.g., how much water is flowing in a river), the actual modelling framework exists out of a set of limited procedures such as equations, i.e., a mathematical model, (e.g., calculation formulas of debit based on dimensions and water flow speed) and the application would be the application of the modelling framework to a case (e.g., calculation of water flow in the river Danube based on input data such as water height). Although we shortly explain these terms in the main text, elaborate definitions of these words in the context of this work are presented in Appendix A.1.

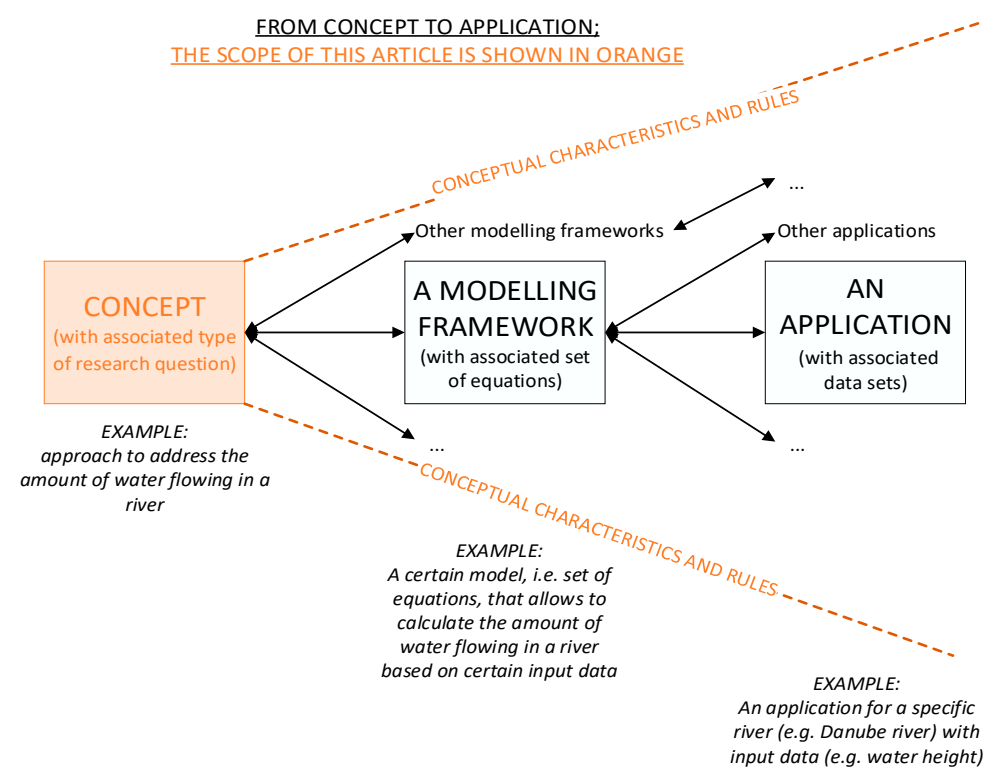

Figure 1. Overview of concept, modelling framework and application notions, illustrated with an example. The focus of our work is on the attributional and consequential LCA methods, more specifically the concepts, its associated characteristics and rules, and the associated modelling restrictions. 
We discuss ALCA and CLCA modelling issues solely in the context of the respective ALCA and CLCA concepts and the specifications and restrictions they impose on the modelling. These modelling restrictions, derived from the concept, are different from (a) other restriction types (e.g., restrictions that are practical in nature, such as data availability or resource constraints) and (b) related modelling parameters and choices, among else based on those other restriction types. For example, the modelling choice to exclude the effect of evaporation (e.g., because of lacking data) in the assessment of the amount of flowing river water is different from the rule that limits the modelling effort to rivers. In the case of ALCA and CLCA, a modelling choice would be the exclusion of certain emissions because of lack of high-quality data. Within the restrictions set out by rules, there is often still room for making modelling choices or different modelling parameters, which lead to having different possible modelling frameworks. Failing to stick to these given modelling restrictions, imposed by the concept, does in the strict sense imply that a modelling framework or application is not in line with the totality of the initial concept and does not completely address that particular research question. Note that it can also be that a concept is further specified to answer a more specific research question (e.g., what is the amount of water flowing in case of a river with a width larger than $30 \mathrm{~m}$ ?), leading to further specifications of the modelling framework and application. Here, we focus on the ALCA and CLCA concepts in general, which are further specified subconcepts from the overarching LCA concept.

In this paragraph, we summarize what is not in the scope of this study. This article does not cover a complete elaboration on existing ALCA and CLCA modelling efforts (and their mathematics) and how to conduct them, nor covers exhaustively examples on applications. Other works focus on such matters, such as the review of Palazzo et al. [5] for CLCA. We focus on presenting the modelling restrictions for these modelling efforts and techniques. Furthermore, our article focuses on principles and is not a practitioner's guide that elaborates stepwise how to conduct an ALCA or CLCA. The extent of data availability and uncertainty for either ALCA or CLCA, is also not part of our analysis. Furthermore, any value judgement or evaluation of relevance of either ALCA or CLCA, e.g., in the decision context or the context of responsibility, is outside the scope of this work.

1. Overall, literature is covered throughout the article, and this article considerably covers existing studies and findings, but also goes beyond them. Specifically, the novelty of this work is twofold: Systematic selection of definitions of ALCA and CLCA concepts from existing ones in an elaborate manner and a further explicit and structured specification of different aspects (e.g., which type of mathematical relationships are allowed or can it cover past or future impacts). For each of these aspects, as already mentioned above, we will specify conceptual characteristics and rules that delimit ALCA \& CLCA modelling frameworks.

2. We envision to present a broader overview than existing studies, as these have selected a definition from certain reference(s) without argumentation, or deal about only some aspects (e.g., only land-use baseline [6]) or mainly only one approach (e.g., only CLCA [7]). The intent is to cover all relevant aspects that were highlighted in literature or were relevant, this in a highly structured way. This completeness is an envisioned novelty. For each studied aspect, the objective is to compare literature considerations, evaluate them and advance reflections beyond literature, thus looking beyond what is currently handled, providing new insight.

The subsequent section, Section 2, of this work elaborates on the existence of various definitions of attributional and consequential LCA (including coverage of literature on definitions) and argues for the selection of one set of these based on certain criteria. In Section 3, essential differences in terms of characteristics and rules between both approaches for certain aspects (e.g., whether future products are considered), are discussed to give a better insight into their nature. In the fourth section, we conclude the analysis and provide a further outlook. 


\section{Specification of Attributional and Consequential LCA Concepts}

Before addressing the distinction between ALCA and CLCA, we will succinctly bring forward some essential aspects and terminologies of the overarching LCA concept, following as much as possible ISO 14040-14044 [8,9] but leaving room for the difference in interpretation between ALCA and CLCA. Although these ISO-documents are about 15 years old, they are still the main reference on LCA that is agreed upon at an international level. Yet, it should be considered that ISO 14040-14044 standards were at the moment of writing under revision, so a strict adherence to the current versions shall be put in perspective to some extent. Furthermore the ISO 14040-14044 standards do not mention ALCA and CLCA explicitly, which makes it challenging to follow them to the letter in light of this elaboration. There is a short mentioning of two different approaches which closely relate with the ALCA and CLCA concepts (Annex A of 14040), but they are not named as attributional or consequential.

In LCA, the environmental impact is characterized for a certain product system, a part of the human/industrial system (collection of specific economic or human-controlled processes). Although "environment" may be interpreted in a more broad way (everything but the human/industrial system), the environmental impact in LCA conventionally is restricted to impact on three areas of protection: Human Health, Natural Resources and Ecosystems [10]. The "environment" is thus in LCA restricted to environmental processes that lead to impact on these three areas. In the ISO 14040 documentation, the wording "potential" environmental impact is used instead of environmental impact as it is (1) a relative expression to a certain amount (also presented as a footnote in 14044), (2) the integration of environmental data over time and space, (3) the inherent uncertainty in modelling of environmental impact and (4) the fact that some possible environmental impacts are clearly future impacts. We agree with this potential nature but find this implicit; when we speak of "environmental impact", "potential environmental impact" is implied. Moreover, any outcome, also process amounts, environmental burden, flows etc., can be considered as potential in nature, based on some of the latter arguments from a scientific perspective, which would out of consistency then also necessitate the use of the word "potential", but this has not been done.

LCA focuses on a certain set of products (including services), that provide a certain functionality, provided by the product system. More precisely, the functional unit represents the "quantified performance of a product system for use as a reference unit" and "defines the quantification of the identified functions (performance characteristics) of the product" (ISO 14040), e.g., white light from a point source with 1500 lumen for $100 \mathrm{~h}$ or a $100 \mathrm{~m}$ swim in a swimming pool of $30 \mathrm{~m}^{3}$ at a temperature of $20^{\circ} \mathrm{C}$. These functionalities can be fulfilled by (a) certain product(s) or service(s), e.g., light (bulb) and a heated swimming pool. A functional unit can cover multiple functions and can also be linked with a single products or multiple products that provide those. The focus is not the environmental impact of the product use as such, but rather that of the complete product system that is linked to it. The focus of LCA is commonly on products, but can be seen as broader (e.g., the products used by an average household in one year). What the product system entails, is discussed in the next subsections, as are the aspects in which ALCA and CLCA differ. In LCA, the inventory of this product system and all its flows is called the life cycle inventory (LCI). The environmental pressures that cross the system boundary (e.g., $\mathrm{CO}_{2}$ emissions), also called elementary flows, of the product system solely make up the LCI table. Within LCA, subsequent to the obtainment of the LCI table of the product system, is the calculation of the environmental impact (e.g., increase in global warming because of $\mathrm{CO}_{2}$ emissions), i.e., the environmental processes that lead to impact on human health, ecosystems and/or natural resources starting from these environmental pressures. See Figure 2 for an overview. Keep in mind that the necessity for a boundary between product system and environment, and thus assigning certain flows and processes (e.g., agricultural processes) to either LCI or LCIA, is disputed [11,12]. This distinction is crucial and has an impact on the modelling specification for ALCA and CLCA, as discussed further on 
(Section 3.7). There is also the possibility for considering feedback loops between LCI and LCIA phases [12-15], e.g., $\mathrm{CO}_{2}$ emissions influence its atmospheric concentration and thus industrial biomass production, which is not excluded in the ISO 14040-14044.
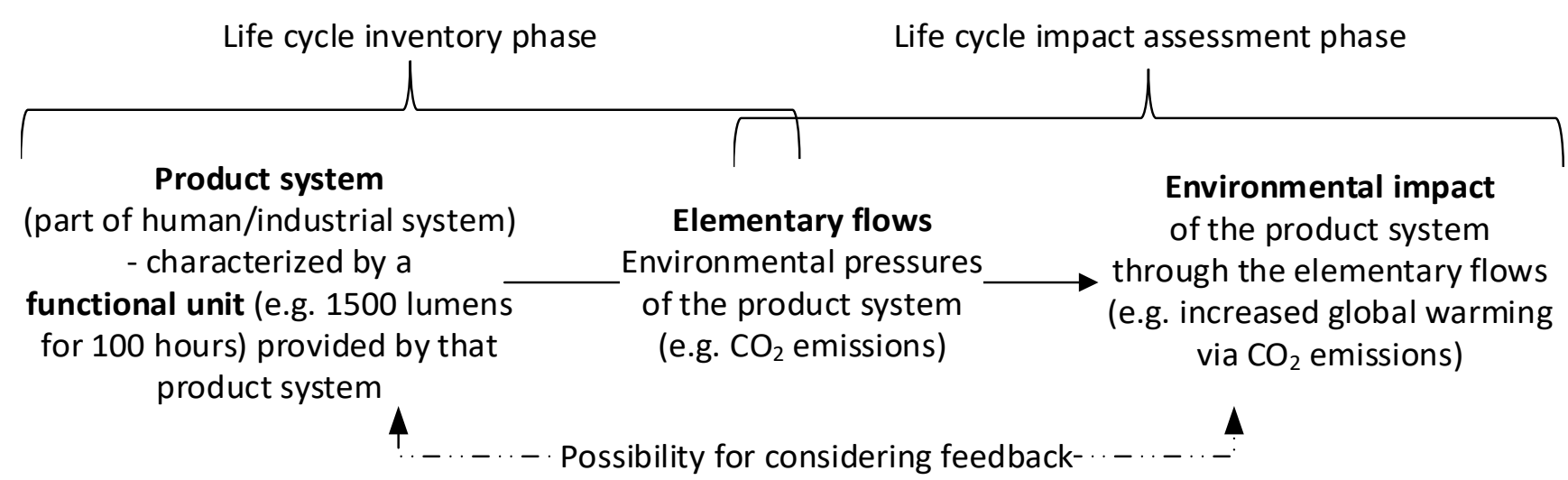

Figure 2. Some basic aspects of Life cycle assessment (LCA), following as much as possible ISO 14040-14044 [8,9] but leaving room for the difference in interpretation between ALCA and CLCA, e.g., the product system is not uniquely defined here.

This short elaboration is a broad conceptual interpretation of LCA and not narrowed down to a fixed model, this to pave the way for a better interpretation of the attributional and consequential LCA types, which are subconcepts. After all, the concept and research question of LCA can be made more specific. Related with the LCA concept, the main overarching research question of LCA as a whole is "what is the environmental impact of a product system associated with a certain product?". The LCA concept can be further specified to relate with more concrete questions, e.g., concerning "what is the environmental impact if I buy this product?" or "what is the environmental impact of all interlinked processes of a product?" or "what is the impact on forest ecosystems of this product system?". In line with this, LCA also covers a Goal and Scope phase, according to ISO 14040-14044, in which the research question and scope of the study needs to be further defined. In light of this, it is imperative to realize that LCA is not a conclusive method in the sense that there is still room for modelling choices. Baitz et al. [16] argue in favor of having these since "restricting the possibilities reduces useful applications, information, and result exchange, learning curves, and communication of LCA and its (positive) impact overall". The existence of different approaches is also underscored in the ISO documentation by the archetypes explained in annex A of ISO 14040, and also through the plethora of different LCA types presented by Guinée et al. [3]. The specification of a Goal and Scope will further delimit these modelling choices. ALCA and CLCA are thus types or subconcepts of LCA, which will be explained further on, addressing more specific research questions, with more restriction of modelling frameworks. Keep in mind, that also more specific subconcepts and questions could be considered for ALCA and CLCA separately.

\subsection{Selecting the Most Appropriate Definitions}

An issue that makes matters more complicated is the lack in consensus on the core goal and concepts behind the terminology of "attributional" and "consequential" LCA. The ambiguity and need for fixed definitions, are for example pointed out by the historical analysis of Porcelli et al. [4]. Hence, it would be good to first consider an overall analysis approach to evaluate different existing definitions of ALCA and CLCA. The focus of this analysis is not on how the concepts and definitions were conceived and who brought forward first conceptual aspects, but on the evaluation of existing prominent definitions. Here, a definition is an exact combination of words that describes a concept associated with a name given to that concept. In general, the criteria for the correctness of a definition, i.e., the linkage of a scientific concept with a name, considered in our work are: 
(a) Logic criterion: the underlying concept should be logic, in the sense that it does not contain contradictions (e.g., a concept that describes that A is bigger than B but also the opposite, is not logic). This does not mean that the concept cannot be abstract.

(b) Name criterion: the concept should be as much as possible in line with the name (e.g., a bad choice in name would be "red bikes" for a concept on blue painted bikes)

(c) Consensus criterion: the definition and concept is supported by a broad community for communication based on consensus (e.g., we call an animal of the species Canis lupus familiaris a "dog" because of convention).

(d) Application criterion: the concept should be in line with the application of the concept (e.g., if a pencil is mainly used to write and not to scratch your back, then the main concept behind a pencil's utility concerns a tool to write).

The Logic criterion is quintessential to consider, especially in a scientific context. The Consensus criterion is crucial to any form of consistent communication at group level and exemplified in the LCA community by the existence of ISO standards and UNEPSETAC documentation. The criteria are also separately brought forward in literature, e.g., the name criterion by Yang [17] and the application criterion by Suh and Yang [18], this specifically in the context of ALCA and CLCA definitions as made clear in the further paragraphs. However, our overall analysis with different criteria for a definition selection, goes considerably beyond limited coverage of criteria and argumentation in literature. The first two criteria, the Logic and Name criteria, are theoretical ones, of which the Logic argument is a necessity (i.e., a definition needs to be logic or it is discarded) while the Name criterion is optional to consider. For optional criteria, it could be acceptable if they are not met, although it is better to meet them. The Consensus and Application criteria, are pragmatic and entail that an evaluation of words is not purely scientific, but based on convention, i.e., it is not about identifying the definition with the most valuable concept from a scientific perspective. These criteria are not a necessity but regarded as more relevant than the Name criterion, in this context, since it might be difficult to find the right name for a complex concept. Most importantly, only the Logic criterion is a necessity with the other criteria being optional to consider, though it is best to adequately meet them, as yet mentioned. In this sense, the optional criteria will help to point out the better definitions if multiple logic ones are available.

In the case of differing concepts, that are logical and associated with the same name, each of those concepts may have a different degree of acceptance and application. It can even be that the concept behind a name has changed over time, and that these changes are in contradiction with the concept of the original inventor. In our case, this seems possible as a considerable amount of time has passed since the original introduction of the words "attributional LCA" and "consequential LCA" [14,19-22]. A restriction to the original definition could be made if the wording is copyrighted and there is one single set of definitions, but this seems not to be the case. In hindsight, it might have been better that different names were assigned to new concepts, which has been partially the case, as demonstrated by the alphabet soup that Guinée et al. [3] discuss. Overall, a lot of logic and potential concepts behind attributional or consequential LCA have been brought forward in the literature [7,18,23-31], which meet the logic criterion and possibly utilize the Name criterion, e.g., the attributional approach is mentioned as the descriptive approach in UNEP-SETAC [31]. Some of these definitions may seem similar but often contain subtle differences that constitute different interpretations.

Since a lot of definitions already exist, it seems most relevant to pick one of these (cited above), instead of specifying a new one. The large current set of definitions seems to already cause confusion. Not agreeing on any at an LCA community level, may maintain confusion, hinder clear communication and hinder advancement. Yang [17], whom explicitly focuses on the Name criterion, highlights that the word "attribution" by definition implies causality, i.e., consequential. As one interpretation of the word "attribution" this can indeed be true, but the Name criterion is optional and that does not mean that the word "attributional LCA" is in practice associated solely with that meaning, i.e., overlooking the Consensus 
and Application criteria. It also implies the loss of an original concept, that of attributional LCA (as defined further on), just by its questionable name. Furthermore, there are other meanings of the word "attribution" that do not focus on causality/consequentialism, e.g., "the action of regarding a quality or feature as characteristic of or possessed by a person or thing" [32].The latter might be more in line with the definition we argue further on.

Considering the above cited selection of definitions of ALCA and CLCA, there are only few interpretations supported by a broad group of people, i.e., following the Consensus criterion, and applied by many, relating with the Application criterion. Concerning concepts that would adhere to the Consensus criterion, this would be those presented in the UNEP-SETAC report [31] report and the ILCD handbook of the JRC-IES [28]. Of the latter two, the first originates from a community supported by the globe and the latter by the European Union. While these documents are a decade old, they contain the most internationally agreed upon ALCA and CLCA definitions. No similar work with that level of representativeness has been published, making them the most relevant according to the consensus criterion. Even though both documents were reviewed by not everybody from the scientific community, from a representativeness perspective, the UNEP-SETAC [31] document may be regarded as more relevant because it is a global entity and we will, consequently, firstly and mainly consider the definitions of UNEP-SETAC [31]. Moreover, Ekvall et al. [26] have criticized the ILCD handbook of the JRC-IES [28], and pinpointed a crucial issue, which will be further handled in Section 3.6. The ISO 14040 [8] and 14044 [9] standards on LCA are also broadly supported but, as already mentioned, do not exactly specify the terms "attributional" and "consequential".

When it comes to the Application criterion, it is also relevant to point out that sometimes ALCA results easily may or have been used as if they would be CLCA results $[17,29,31,33]$. We consider this as a misinterpretation of ALCA results (which is not acceptable) or approximation of CLCA with ALCA outcomes (which can be acceptable because of pragmatic reasons), but therefore we disagree that both approaches address the same matters and the concepts should be merged as Yang [17] seems to suggest. Moreover, Suh and Yang [18] argue that there is a spectrum (instead of the ALCA-CLCA dichotomy) and that applied LCA approaches have been a combination of both. There may be a spectrum in practice, in which aspects of attributional modelling is used to answer consequential questions and vice versa, but this therefore does not intentionally coincide with a spectrum in theory and in concept. Practitioners may have done this out of practical reasons, without a theoretically correct alignment with a certain defined LCA concept and research question. As it is now, there are only two clearly defined concepts (ALCA \& CLCA) on which we focus in this study, but, alternatively, indeed, new concepts could exist or be developed, possibly being a combination of ALCA and CLCA concepts. Yet, in those cases, one needs to define clearly this specific (new) concept with an associated alternative research question. Alternatively, the practitioner should be explicit on his assumption to apply certain attributional modelling to approximate a consequential question, or vice versa.

Another conception, related with the Application criterion, is the restriction of CLCA to only economic- or market-related consequential effects because some works and original theories seem to only focus on this matter [25,34], which might have given this impression (despite the fact that the respective authors may not have had that intention). For example, equilibrium modelling has often been used in CLCA to cover the change in market prices and subsequent effects, but there are other types of consequential effects that can be considered. No such restriction is made in common definitions of CLCA [7,18,23-29,31]. There thus appears to be quite some confusion and inconsistency as to what ALCA and CLCA entail, from an application criterion, and therefore the Application criterion is not considered as determining.

To conclude this analysis, mainly because of the Consensus criterion, the UNEPSETAC [31] definitions are selected. These definitions are specifically mentioned in the first chapter of that work [35]. However, a combination of characteristics is mentioned in 
that report, not a single definition. In Table 1, the core characteristics of the definitions of ALCA and CLCA as brought forward in the UNEP-SETAC report [31] are presented, namely the objectives and the specifications of the product system. These main aspects altogether constitute the definitions/concepts of both ALCA and CLCA.

\subsection{Basic Definition Explanation}

Having fixed the definitions of ALCA and CLCA to those of UNEP-SETAC [31], let us now analyze these. A common representation of attributional of and consequential LCA is brought forward by Weidema [21] and also present in the UNEP-SETAC [31] document. See Figure 4A. Consider the complete human/industrial production system with an associated total environmental impact (the full pie). The attributional LCA then attributes a share of this total environmental impact to a certain product or products, and their life cycle (this impact is represented by the piece of the pie). The respective functional unit may thus entail the functions of different products. The sum of the environmental impact of all separate product life cycles of final products would then result in the total environmental impact. This additivity rule has a considerable impact on the product system in ALCA. See Sections 3.2, 3.4 and 3.5. The consequential approach alternatively analyses how a decision (e.g., a change in product demand with a related functional unit) can change the global environmental impact. It thereby analyses how the decision changes the human/industrial system and its environmental impact at a global level. This is illustrated by the darker color in the second circle in Figure 4A. This distinction does not mean that ALCA cannot cover the impact in a changing world but rather that the functional unit or rather product life cycle has not induced a change. In the definition of ALCA in Table 1, there is no explicit mentioning of decision, change or consequential-related notions. A share of the global impact, which could potentially change over time, is covered in ALCA, but not the change as such. Conversely, in CLCA the decision will induce a change in the world, and it is that global change that is covered. Focusing on a car as a product as an example, ALCA would consider the share of the environmental impact over its complete life cycle of the total environmental impact of a world where the car is already present or at least hypothetically present, whereas CLCA would focus on the effects of a decision to have for example one more car on the environmental impact of the world in which the demand for that particular car was not yet occurring.

Another distinction is that the UNEP-SETAC [31] definition of CLCA is not uniquely specific towards a product demand or a change in production volumes, but concerns decisions in general (which could also be: "should I dispose my product in the nature?" or about deciding to continue or discontinue an activity). In the respective guidelines, it is mentioned that CLCA is "usually represented by changes in product demand", but the world "usually" implies that it is not restricted to product demand. A functional unit can though always be linked, e.g., the function of getting rid of waste or the function that the product would fulfil in case of a decision to cease production, but for which another alternative product will then have to provide that function. For an example on propagation of the cause-effect chain and on another type of decision than extra product demand, please see the CLCA study of Schaubroeck et al. [36] which examines the impacts caused by a replacement decision. Keep into account that CLCA may induce avoiding certain impacts, implying that a negative outcome value is obtained. For example, the decision to innovate a car to lower its environmental impact while maintaining the same performance, implies the avoidance of impact that would otherwise occur if the decision was not taken.

Based on these definitions, one might think the concepts could be coupled. However, because of their conceptual differences, we must also note that a coupling of complete ALCA and CLCA approaches (i.e., effectively linking these methods or making one dependent on the other), as Brander et al. [37] propose, is not interesting since complete other effects could be considered based on the ALCA and CLCA concepts, e.g., changes in market prices and their effect on product trade and amounts induced by a decision or product selection, are covered by CLCA but not by ALCA. An ALCA study could 
be informative for conducting a CLCA or vice versa, but an actual methodological coupling in practice, does not make sense from a theoretical perspective because of their conceptual difference.

Table 1. Definitions of attributional and consequential LCA based on the UNEP-SETAC [31] report. The combination of these characteristics constitutes the concepts of ALCA and CLCA. For ALCA the product system is equal to the product life cycle (see Section 2.2.1).

\begin{tabular}{|c|c|c|}
\hline & \multicolumn{2}{|c|}{ Definitions } \\
\hline & Which Objective or Question Does It Address? & Specification of Product System \\
\hline Attributional LCA & $\begin{array}{l}\text { "The attributional approach attempts to provide } \\
\text { information on what portion of global burdens can be } \\
\text { associated with a product c (and its life cycle)" [31] }\end{array}$ & $\begin{array}{l}\text { "The system analysed ideally contains processes that } \\
\text { are actually directly linked by (physical }{ }^{a} \text {, energy, and } \\
\text { service }{ }^{b} \text { ) flows to the unit process that supplies the } \\
\text { functional unit or reference flow" [31] } \\
\text { "In theory, if one were to conduct attributional LCAs } \\
\text { of all final products, one would end up with the total } \\
\text { observed environmental burdens worldwide" [31] }\end{array}$ \\
\hline Consequential LCA & $\begin{array}{l}\text { "The consequential approach attempts to provide } \\
\text { information on the environmental burdens that occur, } \\
\text { directly or indirectly, as a consequence of a decision (usually } \\
\text { represented by changes in demand for a product)." [31] }\end{array}$ & $\begin{array}{l}\text { "In theory, the systems analysed in these LCAs are } \\
\text { made up only of processes that are actually affected by } \\
\text { the decision, that is, that change their output due to a } \\
\text { signal they receive from a cause-and-effect chain } \\
\text { whose origin is a particular decision" [31] }\end{array}$ \\
\hline
\end{tabular}

a: Physical can pertain to the notion of physical in science, which encompasses both energy and material flows. However, in this definition "energy" is already explicitly mentioned, hence, it relates most likely with another interpretation that delimits it to material: "existing as or connected with things that can be seen or touched" [38]. In any way, both material and energy flows are covered, and the total meaning of the definition does not alter if "material" or "mass" would be used instead of "physical". b: Services cover non-physical economic exchanges that are needed for a process, e.g., the transportation process of a good or the marketing process needed to sell the good (this is a further explanation that is not part of the UNEP-SETAC [31] report). ${ }^{c}$ : In this definition only a single product is mentioned, but in the definition of the product system "functional unit" is mentioned, which may cover various products, and in the UNEP-SETAC [31] document they bring forward system expansion, which also covers multiple products. Based on the latter, we presume this must be a minor mistake in the definition and that it should rather be associated with multiple products, and it should rather be "(a) product(s) (and their life cycle)"

\subsubsection{Difference between Product System and Product Life Cycle Definitions}

In order to further discuss the specifications of ALCA and CLCA according to the UNEP-SETAC [31] definition, we address a discrepancy in the definitions of "product system" and "product life cycle". In the ISO 14044 standard [9] a distinction is made between product "life cycle" and product "system". Product life cycle is defined in the ISO 14044 report as "a consecutive and interlinked stages of a product system, from raw material acquisition or generation from natural resources to final disposal". A product life cycle may thus cover various final demand products and their life cycle stages from natural resource extraction up until final disposal; the functional unit can constitute multiple functions from multiple products (see beginning of Section 2). A product system is defined as "collection of unit processes with elementary and product flows, performing one or more defined functions, and which model the life cycle of a product". These two definitions refer to each other and are difficult to separate (This is an issue in the interpretation of latter definitions. UNEP-SETAC [31] seems to have mainly specified the "product system" definition and not the "product life cycle" definition, but then also avoids above referral issue. The ALCA and CLCA product system definitions of UNEP-SETAC [31] do not mention "product life cycle" (see Table 1). As already argued in Section 2.1, we thus start here from the "product system" definitions of UNEP-SETAC [31], but we still consider "product life cycle" from ISO 14044 as defined above, but then without referral to product system. The considered definition for a product life cycle is then: "a consecutive and interlinked stages, from raw material acquisition or generation from natural resources to final disposal". (The recent 2020 amendments of ISO 14040 \& ISO 14044, define a life cycle as "consecutive and interlinked stages, from raw material acquisition or generation from natural resources to 
final disposal", but do not alter the definition of product system, which implies that a product system is still considered equal to a product life cycle.)

For ALCA, there is no difference between the specification of product system by UNEPSETAC [31] and that of "product life cycle" by ISO 14044 [9], if "raw material acquisition or generation from natural resources" is expected to be up until the final preceding interlinked processes and "final disposal" up until the last proceeding interlinked process. In this sense, in Table 1, the definition of product system is equal to that of product life cycle in ALCA. Both the product system definition of UNEP-SETAC [31] and product life cycle definition above, entail the product life cycle. The only issue would be that in the objective definition only a single product is mentioned, but in the definition of the product system "functional unit" is mentioned, which may cover various products, and in the UNEP-SETAC [31] document they bring forward system expansion as an approach (see Section 3.5), which also covers multiple products. Based on the latter, we presume this must be a minor mistake in the definition and that it should rather be associated with multiple products, and it should thus rather be "(a) product(s) (and their life cycle".

For CLCA, It is quite clear that these two specifications of product system, of the ISO 14044 (which "needs to model the life cycle of a product") and UNEP-SETAC [31] (which does not need to model the life cycle of product), and thus associated concepts, do not completely align. It may be that a complete product life cycle is not covered in a product system of CLCA, e.g., the decision to buy an existing car will not have as consequence the production of that particular car (the consequences of a decision cannot go back in time), but maybe of others (See Figure 3). See for example the work of Schaubroeck et al. [36]. An exception would be if "needs to model the life cycle of a product" is excluded from the definition of product system. This delimitation of the product system is different from the product system which normatively consider a product's life cycle. Moreover, a product life cycle could be seen as the result of a collection of decisions, from the decision to extract resources to the decision to dispose the good in a certain way. However, this is not guaranteed in reality. In CLCA, each of those decisions, a set or all decisions altogether can be evaluated in their specific context to study the additional global environmental impact they induce. Yet in the annex A of ISO 14040 a definition of product system of that of CLCA is implied, contradictory and inconsistent with the one in the ISO 14044 main text. See Section 3.9.

The lack of agreement on a general product system definition for CLCA seems to be also present in the literature, and thus at the level of the scientific community. Hertwich [39] though mentions in the context of CLCA that "a product system comprises the activities required to deliver, utilize, and dispose of a product", which seems in line with the "product life cycle" definition of ISO 14044 and going against the "product system" definition of CLCA of UNEP-SETAC [31]. The decision in the approach of Hertwich et al. [39] seemed to be narrowed down to an "increased demand of a certain product life cycle", in which "product life cycle" would then relate to the definition of ISO 14044. The product system would then include additional consequential mechanisms in the human/industrial system besides a normative product life cycle. See the middle graph of Figure 3 for an illustration of this other approach. This disagreement reflects also somewhat the issue that the ISO 14040-14044 reports make no exact distinction between ALCA and CLCA (terms "attributional" and "consequential" are not mentioned), implying a lack in agreement of standards, and that the ISO 14040-14044 is maybe just mainly the interpretation of ALCA. Yet, the latter can also be questioned. See Section 3.9. A real solution and agreement on these terminologies should be obtained through an agreed-upon revision or adaptation of the ISO or UNEP-SETAC report [31], or a combined effort. 


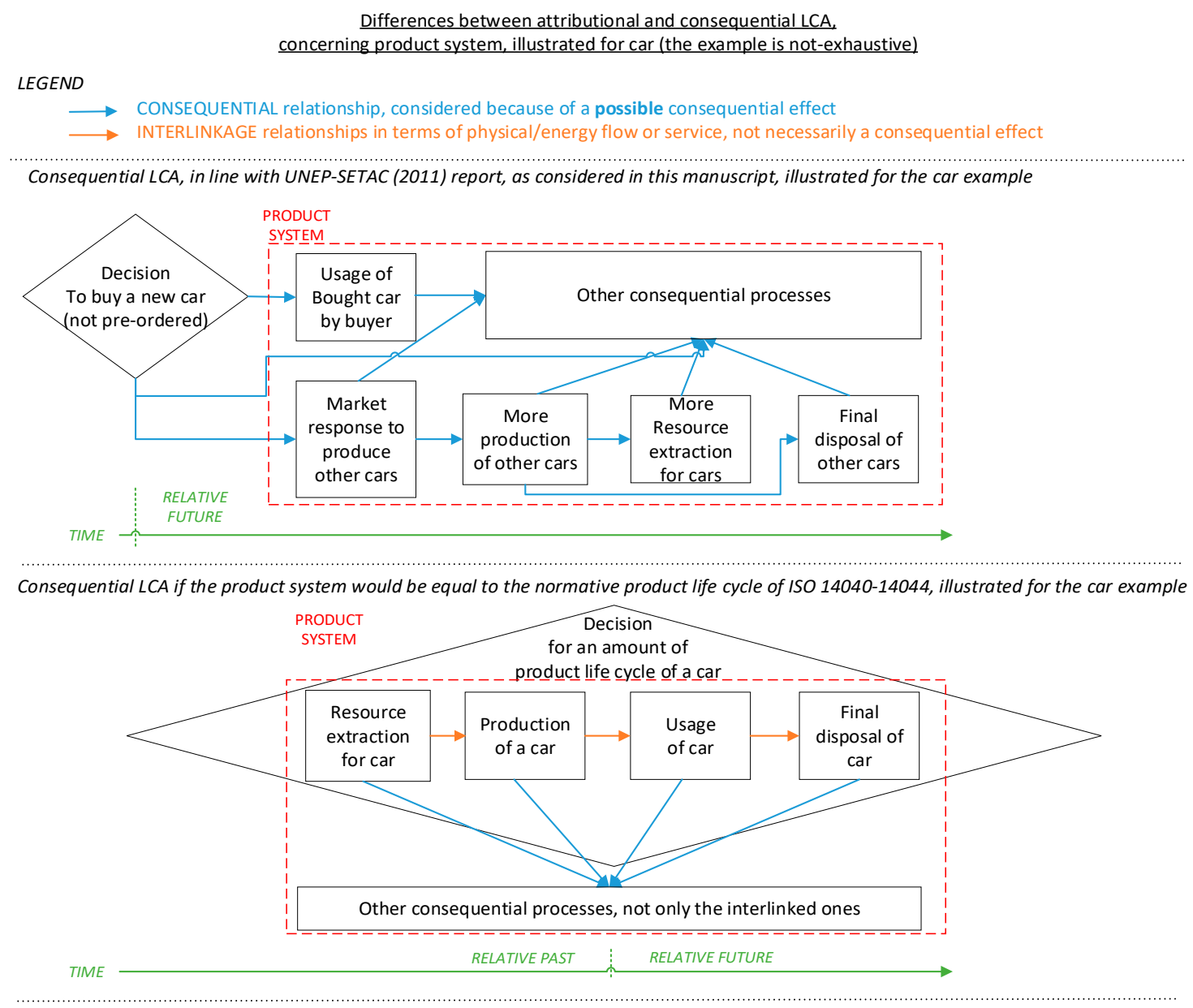

Attributional LCA, in line with UNEP-SETAC (2011) report, as considered in this manuscript, illustrated for the car example PRODUCT

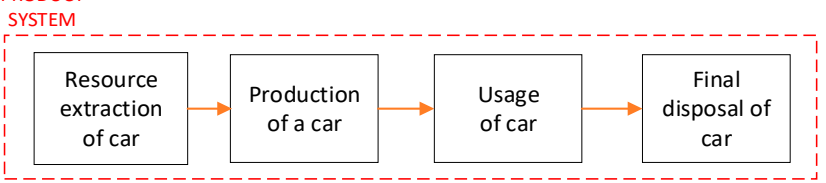

TIME

RELATIVE PAST

RELATIVE FUTURE

Figure 3. The figure presents the difference between the notion of product system in case of attributional LCA, consequential LCA (following UNEP-SETAC [31]) and consequential LCA if the product system needs to cover a product life cycle. The arrows and boxes are not exhaustive, i.e., not all processes and relations are shown. In case of the CLCA which encompasses a product life cycle, further consequential effects are considered within the product system, but here no processes are shown. The time axis (in green) showcases that consequential LCA considers only the relative future after the decision and not the past (i.e., no relative past processes are considered), whereas the attributional LCA considers the relative past and future with product usage as reference point.

Throughout the rest of the article, we will mainly focus on product system (instead of product life cycle) and consider the CLCA concept of UNEP-SETAC [31] based on the reasoning presented in Section 2.1. We elaborate more on the aspects of consequential, causality and interlinkage of the product system in Section 3.1.

\section{Different Conceptual Characteristics and Rules for Various Aspects}

In the following subsections, crucial aspects are discussed in order to better characterize these concepts, but also to specify conceptual rules and the extent to which they specify and limit modelling frameworks. Hereto we follow the UNEP-SETAC [31] definitions to the letter. 


\subsection{Relationships and Boundaries of the Product System}

Crucial in LCA is the delimitation of the product system, against which the associated environmental impact is assessed. Based on the UNEP-SETAC [31] report (see Table 1), this matter is quintessentially different between the ALCA and CLCA approaches. As mentioned in Table 1, in a CLCA, the product system consideration is consequential-driven, i.e., one process is a consequence of a previous one, starting with the decision, implying consequential relationships (see Figure 3). A consequential relationship entails a specific aspect of causality. More precisely, as also brought forward in literature [36], we interpret the concept of "consequence" as the result of an action, performed in a specific context, and this result occurs after this action. This brings the concept of "consequence" in line with Mill's [40] three conditions for causal inference: (i) time precedence of the cause, (ii) association of the cause and effect, (iii) absence of other plausible causes [41]. If A causes $B$, it might not mean that A therefore will again occur if B occurs. When researching the consequences of a decision, we do not research what has caused this decision, but only research its probable subsequent effects afterwards. Applying consequentialism to the product system thus means that effects (flows or processes) are included in the product system to the extent that they are probably brought forward afterwards by other ones, e.g., burning a fossil fuel leads to creation of $\mathrm{CO}_{2}$, starting with the decision in case of CLCA. The derivation of this consequentiality is thus also susceptible to uncertainty and probability. In other words, we are not sure about the occurrence of processes and their amounts can commonly not be exactly derived. For example, the decision to discard waste in the nature may induce its collection and treatment (e.g., $50 \%$ probability), but it may as well just be left there (e.g., 50\% probability). A decision, as part of the general UNEPSETAC [31] definition, may induce the complete similar life cycle of a product, as defined in the ISO 14044 report, but this is not guaranteed. For example, consider the decision to buy a readily available car which has been produced prior to this decision. This purchase will most likely consequently induce the processes of usage and this process may in turn affect other activities, but it will not have induced the production of that particular car because that occurred prior to this user's decision. However, a subsequent possible response to this decision may be the production of one or several additional cars by the market. Moreover, this thinking should be expanded towards the whole cause-effect chain. The car production and usage may use existing products such as gasoline, for which the production may have already been done and should be excluded, yet, further induced production of new products, e.g., gasoline, should be considered. Another example would be that in order to produce a car, an assembly line of machines is required, and the production of this car depletes the capacity of these machines which may lead to their replacement in the future. See the article of Schaubroeck et al. [36] where a framework is presented in which the effect of a replacement decision is propagated further in time, including the market response of producing more cars when buying a new one.

In ALCA, the relationship is characterized through linkage (limited to "physical, energy and services" flows) which means that if process A and B are linked by a flow both will be considered. In ALCA, the product life cycle and thus product system is, as described in Table 1, a chain of processes interlinked that provide the functionality needed. This aspect of interlinkage means that there is a connecting flow, but implicitly there always is a consequential relationship between interlinked processes, as there would otherwise not be a link. However, while in CLCA, only affected consequential processes after the moment of decision are included, in ALCA it is possible to also include preceding causes: processes that have caused another process. In other words, the interlinkage in ALCA can go in both ways: cause to effect and effect to cause, the latter not being consequential. More precisely, no consequential paradigm is followed by the obligatory consideration of interlinked preceding processes for a certain product at a certain point in time in ALCA, as these are not the consequence of the specific product and occur before the existence of the product. 
For example, the process of natural gas burning links with the production of natural gas because of the physical flow of natural gas from one process to the other, not priorily because the specific extraction of that gas was induced by the burning of that particular gas amount, but because it is a probable cause of it. The prospect of burning it could induce its extraction, but not the burning itself as a process, which occurs afterwards. Keep in mind that this interlinkage may also be susceptible to uncertainty and probability, e.g., the effect probability that the particular gas amount will be burned or the cause probability that gas will have been created by a particular process. The included processes and flows in ALCA are thus not only effects but also causes. There can indeed be causality or consequential thinking behind ALCA but this covers the consideration of causes starting from effects, which is not the case for CLCA, while Yang [17] do not distinguish this difference. Moreover, consequential or causal mechanisms can only be considered within the rules set out by "interlinkage" concerning the type of flows, within ALCA. In ALCA, also not all consequential effects can be covered because of those rules, as discussed in the next section. Finally, these rules that defines the product system in ALCA may indeed have been based on consequential thinking upon conceiving, but they are still rules as such. A concrete example in real life: a legal rule to not cross a red light is a rule, but it may have been derived from consequential thinking that it would otherwise create a lot of traffic problems and casualties. Yet, it is still a rule, which is the same for the consideration of a complete product life cycle. Not following the latter rule means not being compliant with ALCA, just like crossing the red light means not being compliant with traffic rules. Yet, jaywalking when there is no traffic around will not cause any negative consequences, but it would still imply the crossing of a rule for which one could get a fine. Likewise, in ALCA, interlinked processes are considered that may not have been induced consequentially, e.g., the production in past when studying a product provided in the present, but are considered nonetheless.

\subsubsection{Types of Flows}

Coming back on the aspects of types of flows, in ALCA, the interlinkage of the product life cycle is through "physical, energy and service" flows (definition Table 1), which encompass thus also services representing economic exchanges, e.g., the transport of a good or the labor needed to sell the good. As already mentioned in the footnotes of Table 1 , "physical" implies that, besides energy flows, material flows are covered. Moreover, as also mentioned in the footnote of Table 1, services cover non-physical economic exchanges that are needed for a process, e.g., the transportation process of a good, the use of capital equipment, the marketing process needed to sell the good or the treatment of waste.

For CLCA, there is no limitation present concerning type of flow in the definition of product system. The cause-effect chain can be induced by any type of flow, going beyond merely physical or service flows. More specifically, this can also be an information flow and relate to behavioral processes, which is not the case for ALCA. Building further on the car example, the extra production of other cars $X$, induced by a purchase decision of car $Y$, is induced by an information flow, and should thus also be considered in CLCA. Furthermore, this implies that a product system is not limited to a product life cycle of one single product. The decision to buy less cars, may, for example, trigger train manufacturers to produce more trains as they anticipate more public transport. Keep in mind that some services, may contain aspects of or consists entirely of information, but not all information flows are services, i.e., not all information flows are payed for as part of a service. In practice, modelling choices are made in CLCA to limit the scope of considered relationships.

\subsubsection{System Boundaries of Product System}

In general, for both ALCA and CLCA, it might be presumed that the boundary may be infinite in theory but in practice "leakage" occurs, which would imply that the total scale of processes decreases because of lowering of amounts due to losses towards the environment, as Weidema et al. [42] mention. This would imply that process quantities 
will diminish upstream or downstream because of losses to the environment, but this will only be the case if only physical relationships are considered between processes, given the laws of conservation. Prominently, in case of closed loop systems (e.g., recycling), flow amounts may just become very small, but are therefore not equal to zero, which implies that the system still is infinite (i.e., an infinite amount of processes is considered). Hence, there is thus commonly a diminishing trend in amounts, when only considering physical/energy flows because of losses, and the total outcome will approximate a finite value. In practice, a numerical cut-off, i.e., flows smaller than a certain amount are not considered, is then commonly applied, which results in an exact finite value and boundary cut-off. Yet, this diminishing trend in mass and energy amounts is not always the case. In both ALCA and CLCA, services are considered, which implies that there is no restriction to physical flows only. For example, if transport is needed as a service, again vehicle and fuel are needed. In addition, there may be a limitation in added value amount, but then still some services are executed by society and not the value chain (e.g., municipal waste disposal is not fully covered in the economic value of the product). Besides, economic balances are not strict, implying that prices may vary over time or economic balances are not closed, which means that this is not necessarily a constraining factor. Furthermore, in CLCA, information flows are also regarded. For example, a car purchase may induce the production of two additional car. These aspects imply that in both cases of ALCA and CLCA, there will not be a guaranteed diminishing effect. In fact, through positive feedback loops (e.g., in case of CLCA, using an electric car, might convince more than one other person to buy such a car, and this could convince in turn other persons etc.), there can be even an increase of the system (and thus also its impact) over time. Furthermore, cataclysmic decisions may have highly likely insurmountable ever lasting effects on the industry, e.g., the decision to construct and operate the first large-scale nuclear fusion reactor, inspiring others to do so as well. In line with this, innovations leading to new or improved products are typical developments that can have more likely a profound and infinite effects, as compared to a world without these. Finally, although the environment may be limited in mass and energy flow, it is not the case for their availability over the infinite time horizon. In practice commonly a finite boundary or outcome is obtained, because of practical restrictions (e.g., data shortage or small cut-offs considered) or the structure of the considered product system, but in theory an infinite product system is definitely possible, even with a runoff-effect.

Overall, an infinite product system with infinite outcome can be obtained, which makes it impossible to identify the more environmentally friendly system among systems with related infinite outcomes. As a consequence, in practice, still artificial boundaries need to be drawn. When it comes to boundaries in CLCA, Ekvall and Weidema [43] mention that "the boundaries of the system investigated should ideally be defined at the point where the consequences are so small, or the uncertainties so large, that further expansion of the boundaries will yield no information that is significant for any realistic decision". From a broader perspective, this is based on the limits of our knowledge of what cause-effect chains could entail $[44,45]$. Coming back on the statement of Ekvall and Weidema [43], their advice is difficult to follow exactly because of the lack of knowledge on the extent of the consequence or the extent of uncertainty. As an aid in pinpointing a cut-off, based on ethical consideration, impacts could be valued less over time, through discounting [46-50], and will then automatically become less significant over time. Note that this consideration uplifts intergenerational equity. However, this only increases the chance that future impacts are lower but does not guarantee it (because of potential increasing product amounts as discussed above). Discounting is not a cut-off approach as such. It would just make a cut-off more acceptable but not conclusive. In fact, the time boundary of 100 years in the Global Warming Potential calculations can be regarded as an ethical consideration that implies that the impacts after 100 years are not of relevance. However, originally, these boundaries may also have been set out of randomness or because of practical reasons, e.g., computational feasibility and output uncertainty and credibility. Similarly, a cut-off boundary of 100 years could be 
set for the product system. This is currently a modelling choice but it would be advised to agree upon a cut-off rule for both ALCA and CLCA (and sustainability assessment in general) at the scientific community level, which could possibly be a cut-off rule over time and potentially in combination with discounting.

\subsubsection{Considered Systematic Cut-Offs in Literature}

Although perhaps not for the above reason of probable infiniteness of the product system, many systematic variants of cut-off rules have been introduced in literature, despite the fact that they are, in a theoretical sense, non-compliant with the definition of a product system. Besides the numerical cut-off, these cut-offs may have value-laden implications, but this is not the focus of our work. Such systematic cut-offs have especially been introduced for ALCA. The most common is the consideration of so called "partial" product life cycles, that only cover a part of the product life cycle, e.g., "cradle-to-gate" studies that only cover processes from initial resource extraction from nature ("cradle") up until product manufacturing ("gate", implied as factory gate). The latter is also specified in ISO 14040 as not being LCA studies, but just a study to which some LCA principles have been applied. "Cradle-to-grave" studies are also mentioned and cover the complete product life cycle of the respective product(s), if by "grave" is meant the final disposal of the product and not intermediate ones after which further processing such as recycling could occur. An approach in which a cut-off is applied after the first waste processing (the "first grave"), is the "cut-off approach" or "recycled content" approach, which is a common system model considered in various databases, standards and guidelines [51,52]. In that method, only waste handling is considered, whereas further conversion into new products are cut off, even though there is a physical link and thus should be part of the product life cycle and product system (see Table 1). A more recent method of attributional LCA, Allocation at the Point Of Substitution (APOS), does not perform this cut-off and traces the complete interlinkage [53-55], in line with the UNEP-SETAC [31] concept of ALCA. Schrijvers [56] review this APOS approach thoroughly and consider it also more appropriate than the cut-off approach to address the ALCA question, since the cut-off approach is not compliant with the ALCA definition and not compliant with ISO 14040-14044. As explained in the text above, because of not covering the final disposal and discarding what happens beyond waste valorization, the cut-off approach is not compliant with ISO 14040-14044. Schrijvers et al. [57] elaborate further on this matter and argue that the cut-off criteria in the ISO for insignificant flows do not consistently validate the cut-off after waste valorization as done in the "cut-off approach as there can be huge impacts downstream". Note that there are other differences between these models, specifically on the matter of multifunctionality (see Section 3.5).

Any of the existing cut-off rules could possibly be considered, but hereto an agreement on a scientific community level is needed, which is lacking in both ISO 14040-14044 \& UNEP-SETAC [31]. Hence, the issue of infiniteness and how to handle it, still remains.

\subsection{Considering Time}

The concepts of ALCA and CLCA, as presented in Table 1, do not have an explicit temporal specification, i.e., it is not mentioned explicitly whether e.g., the past is covered. Yet, temporal differentiation has been studied considerably over recent years in the field of LCA, and is considered an important aspect of improved modelling and interpretation [49,58-61]. A product system is after all spread over time, as is its associated environmental impact. A car can only be used after it has been produced. Therefore, the initiation of the environmental impact of production of a car will precede that of the use of that specific car. When considering the decision to buy an already produced car (not order it), the product system may either encompass the production of the specific car, in case of ALCA, or, in CLCA, exclude this production because it occurs before the decision. However, in CLCA, such a decision may possibly induce the subsequent production of other cars in the relative future, not the production of the specific one that is used (see Figure 4). 
(A)

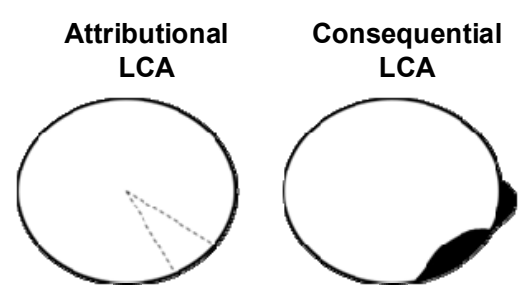

(B)

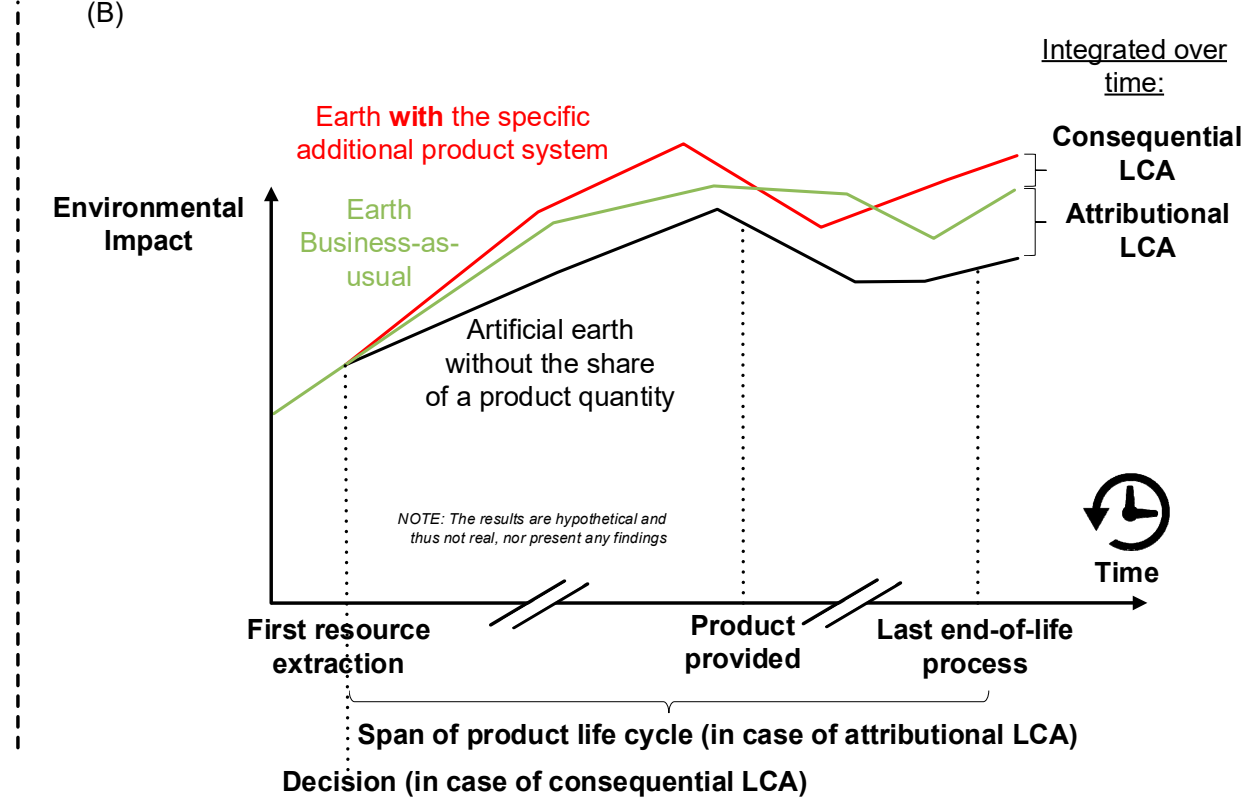

Figure 4. The conventional representation of attributional versus consequential LCA [21] in the left part of the figure (A), in which the circle represents the impact of the entire human/industrial system. The new representation in the figure to the right (B) provides a reflection considering the aspect of time. The presentation in the graph represents a quantification using different scenarios (see Section 3.3). In part B, ALCA of a product quantity is the difference between the business-as-usual (green line) and the artificial earth without that product quantity (black line). CLCA constitutes the difference between the business-as-usual earth (green line) and the earth altered because of a decision (red line) For simplicity, the attributional and consequential approaches are here shown to be initiated at the same time but this is not fixed. There is no link between the product life cycle, in case of ALCA, and the decision, in case of CLCA. The artificial scenario (black line) of ALCA in the Figure will never go higher than the reference scenario (green line). Note that the reference scenario of ALCA may also be something else. which can be seen as another scenario for the Earth.

Yet, from an absolute time perspective, ALCA and CLCA can be used to assess impacts of product systems in the absolute past, present and future [23]. Considering this time perspective, for both attributional and consequential approaches, one should thus specify in the goal and scope phase of the study when exactly the product quantity, change, or decision occurs [60]. The absolute timing of product provision or of a decision, leads to a distinction between subtypes of LCA. If this is done in the past, we speak of a retrospective LCA and when done in the future, a prospective LCA. Although these terms have been linked with ALCA and CLCA, respectively, this does not make sense $[19,21]$. For example, one can also evaluate a past decision (retrospective CLCA). Alternatively, one could also consider what would be the environmental impact attributed to products that are provided in the future (prospective ALCA), e.g., addressing what would be the share of the burden that can be attributed to an electric car used in a future timeframe, e.g., from 2030 to 2040. However, this would require a prospective reference system or scenario to be modelled. This can even be in the consideration of a decision that induces it, e.g., specification of impacts attributed to an electric car in a future world where the decision is made to produce 40 new electric cars, in which the ALCA would though not cover the effect of the decision. Conversely, from a CLCA approach for the decision to produce those 40 new electric cars, the effect of that particular decision would be studied. As Zamagni et al. [7] noted: "we should be aware that these "future" considerations are not a peculiarity of CLCA but can also be dealt with in other LCA modes." However, besides this freedom to select a point in time, choices ought to be made to reflect the actual (or best estimation for the) timing of occurrence. In other words, if we define that a specific product should be delivered at time $t$, the production of that exact product should not occur after time $t$. This does not deal about a product in general (e.g., a car), but about the specific product that is to be 
consumed (the specific used car). Production of another batch, could happen afterwards, as shown in the example for CLCA in Figure 3.

Coming back on the relative temporal perspective, the only difference between CLCA and ALCA, is in the relative consideration of time (not the absolute one). CLCA always considers the time after the decision, the relative future of the decision, even if the decision itself occurs in the absolute past, present or future. The "consequences of a decision" (Table 1) cannot go back in time. Even the whole cause-effect chain along the supply chain, is projected into the future (e.g., buying a car, induces that a car should be finalized or more produced, and this possibly induces car part manufacturers that car parts should be finalized or more produced etc.). As an example, see the work of Schaubroeck et al. [36]. ALCA considers the time before the product finalization (e.g., raw material extraction) and after the product finalization (e.g., disposal), i.e., both relative past and future.

It is mainly regarding the time aspect, that the definitions of UNEP-SETAC [31] differ slightly with that of Guinee et al. [3]. The latter authors specify as a goal of ALCA that it should assess "the environmental impacts of a production system as it currently functions", whereas this limitation to current functioning is not specified by UNEP-SETAC [31] (see Table 1).

Even though such a limitation to "currently functions" could be considered from a normative perspective (not that any other definition ever raised that), it would make the concept more unrealistic, as it could not present a share of the globe anymore that is spread over time. Note that Guinée et al. [3] also present the definitions of UNEP-SETAC [31], but it is then not made clear as to why they present a second definition in their work that doesn't completely align with these former definitions. In practice, the inventory for current functioning may be used as an approximation but we would not present it at a conceptual level. Finally, the consideration of current functioning, is also in contradiction with their statement that "ALCA is the only mode focusing on modelling a situation as it is, either in the past, present, or future, but without any changes" [3]. In this sense, it could be that they mean "currently" in a relative manner, i.e., the time at which a process occurs. Yet, in Table 2 in their work, it is also specified that ALCA is only for past and present, which implies the ignoring of any future effects or consideration of products and functionality in the future.

To conclude, ALCA and CLCA are not restricted by time in an absolute sense because product systems are spread over time and decision and product delivery can be studied at any point in time. However, CLCA only propagates the effects in the relative future of the decision, i.e., after the decision, whereas ALCA also traces back impacts in the relative past, before product provision.

\subsection{Specify the Product System and Impact Separately or Compare Scenarios}

Generally, there are two approaches to conduct a single LCA: (1) quantify separate scenarios of a world or an independently impact section of it (e.g., with and without that product system; the latter called reference system), and compare them, or (2) estimate the product system and its impact within a reference environment (with reference conditions) separately, i.e., quantify the difference between the scenarios directly and not a priori quantify separate scenarios to then compare them. See Figure 5. Keep in mind that this does not deal about the comparison of multiple LCAs, corresponding with alternative product systems, that provide the same functional unit. It will be shown in this section that both approaches for a single LCA can be applied for both ALCA and CLCA, implying no conceptual restriction. The second option is the main approach applied in LCA studies. The product system is modelled separately for each (set of) product(s) or decision alternative(s). In practice, in LCA software, you can easily select a product, for which then a product system is propagated, as well as an associated environmental impact. This reference environment only concerns reference conditions (generated by both the human/industrial and natural drivers), e.g., temperature, pressure and macroeconomic situations, that are ideally not connected or influenced by the product system. Although the latter is in theory 
not possible, if the flows are very low, they may negligibly induce a change in the reference environment, and this effect could therefore be neglected in practice. Ideally, though, a changing reference environment occurs and also the feedback of that on the product system should be assessed (e.g., a temperature increase by greenhouse gas emission in agriculture on the agriculture itself). Hence, the first option is gaining interest because of the complex interconnectivity between product system and its reference environment as mentioned above.

\section{Two alternative ways to assess the impact of a product system}

\section{Compare impact scenarios}

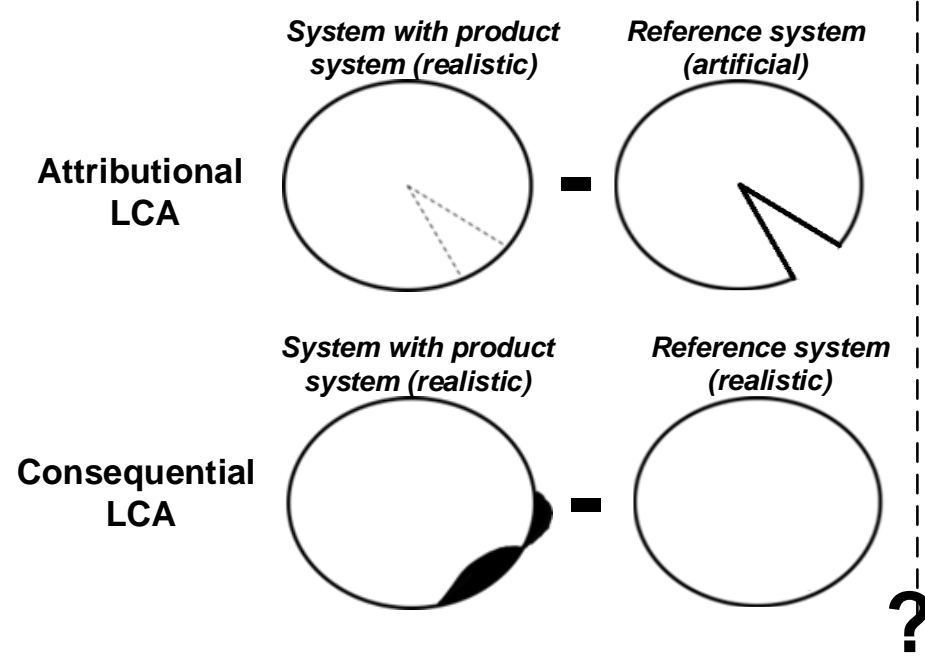

\section{Specify product system impact separately within reference environment}

Here they are depicted the same but the two ways can in practice only approximate the same outcome if the influence of product system on the reference environment, and possibly further feedback, is negligible

Figure 5. Explanation of the two alternative ways to assess the impact of a product system.

Concerning consequential LCA, since it implies the effect of a decision, such an assessment can be easily envisioned to cover the comparison of various scenarios [7,29]. These scenarios, because of consequential effects (e.g., due to greenhouse gas emissions), would then align with different plausible versions of the world. Each one for the different alternatives of the decision. For example, if the decision is just to produce an extra certain amount of a product. In the latter case, consequential LCA then entails the comparison of a scenario with that increased amount compared to a scenario without that additional amount, i.e., a business-as-usual scenario (Figure 3).

Attributional LCA assigns a certain part of the global environmental impact to the studied product life cycle. The above option (2) is a more straightforward way of quantifying an attributional LCA. ALCA could also hypothetically be regarded as a difference between scenarios (Figure 3), as in option (1), but then the scenario without the product system is an unrealistic and hypothetical one, as also brought forward by Soimakallio et al. [6]. This issue is specifically discussed when it comes to the land use baseline to characterize the effect of land occupation in LCA $[6,24,62]$. The land occupation would then be characterized as the loss in ecosystem services and biodiversity which would have normally been provided by the baseline system, as proposed in a UNEP-SETAC guideline [63]. Soimakallio et al. $[6,62]$ are not conclusive but argue in favor of a baseline in which the state before land use is considered and then further natural regeneration occurs, which is artificial as in a realistic baseline scenario possible human intervention (besides the product system) should be considered. The latter type of realistic scenario would be relevant in the case of CLCA. For example, for a decision to construct a building on a piece of land, in CLCA, this is compared with an alternative scenario where the land is not occupied by 
that particular building but possibly used for other realistic human purposes (e.g., parking lot) besides having natural vegetation grow on it.

To conclude, both scenario comparison and direct propagation of the difference can be applied and are not limited by the conceptual characteristics of ALCA and CLCA, but rather pragmatic considerations. The consideration of various scenarios and reference environments also serve as a part of the uncertainty assessment [7].

\subsection{Additivity-Restricted ( $A L C A$ ) versus Free Mathematical (CLCA) Modelling Specifications}

These concepts also delimit the type of mathematical modelling framework that should be apprehended from a theoretical viewpoint. A straightforward modelling assumption is that of linearity. Linearity can refer to different concepts, but here we have a restricted meaning in mind: namely the multilinearity concerning the demanded products as input. A multilinear model is a model in which the output (in this case environmental impact) varies in a linear way if one of the inputs in varied, the other inputs being fixed. Here we consider fixing all process data, and only changing the product amount (which represents the functional unit). Mathematically, the basic function is $Y=a \times X$, where $Y$ is the impact and $X$ the product amount. We further refer to this multilinearity as linearity in the rest of the article. Note that this multilinearity may not hold for other input parameters for the LCA model, more precisely that of the technology matrix, but here we only focus on the final product amounts as input [64]. This is mathematically elaborated in the Appendix A.2. This linearity in a product system would imply that a functional unit of 2000 MJ electricity should imply two times the environmental impact of a functional unit of $1000 \mathrm{MJ}$, if only electricity is considered as product. In the original ISO 14040-14044 [8,9] documents on LCA, no specification is made regarding linear modelling. The UNEP-SETAC [31] definitions of ALCA and CLCA do not explicitly mention linearity. Nevertheless, the main models that are used in LCA methodology are commonly linear, as explained elaborately in literature [65] and illustrated in the Appendix A.2. As brought forward in latter reference, a distinction can be made between process-based, environmentally extended Input Output (EEIO) and hybrid approaches, which follow the same mathematical backbone. Keeping into account the considerations (e.g., modelling restrictions) discussed in this work, these approaches could be used for either ALCA or CLCA. For example, even for EEIO in CLCA, the Stone method could be applied to address multifunctionality [66-68]. We do not further elaborate on these three different techniques as this is out of scope of this study.

For ALCA, the reason for linearity is not only because of easiness of application (e.g., easy upscaling and aggregation of results), but also because it readily meets a theoretical requirement. A prerequisite in the UNEP-SETAC [31] report for ALCA is (see Table 1): "if one were to conduct attributional LCAs of all final products, one would end up with the total observed environmental burdens worldwide". (A final product is considered here a product that is directly consumed by humans and not used in the life cycle of another product.) The specific prerequisite is also reasoned in literature specifically for ALCA. More precisely, prominent works of Heijungs $[14,69]$ bring forward the axiom that results of different final products should be additive. Additivity implies that the sum of the impacts of separate products (through several LCA) equals the impacts of those products all together (through one LCA). As Heijungs $[14,69]$ discusses, to meet this additivity prerequisite, material and energy balances should be respected and this will guaranteed be met through linearity, out of pure mathematical reasons. For example, if one LCA study estimates the environmental impact on five apples and afterwards the same approach is applied for two identical apples, the impact of seven apples will only be equal to the sum of the separate impact of the studies, if the LCA function is linear, i.e., impact $=$ linear factor $\times$ number of apples (since then linear factor $\times 7=$ linear factor $\times 2+$ linear factor $\times 5$ ). If the function would be for example a square function, this does not hold since $25+4$ is not equal to 49 . It is possible that linearity is not the only option to meet the requirement for additivity, but it is guaranteed for a linear modelling framework, which is currently common and practically straightforward. Alternatives need to be further studied and validated. These could for 
example be based on so called "general additive models" (the name does not guarantee it) applied mainly in the field of statistics [70-73]. There might thus be a possibility for non-linear additive ALCA modelling frameworks, but this is not yet validated. In this article we will focus on the linear modelling framework for ALCA.

Moreover, considered amounts cannot be bigger than their total global demand over the considered period, as otherwise they imply going beyond the "total observed burden worldwide" as presented in the definitions of UNEP-SETAC [31] in Table 1. In the definition of ALCA is also mentioned that a "portion" is considered, and a portion cannot be bigger than the total of which it is a part of. It is important to note that this additivity, in the strict sense, is valid per life cycle and that each life cycle should then also be linked with just one final product. To validate this additivity, it should be checked whether the reference products of to-be-added ALCA studies are final products and are, in other words, not consumed in the life cycle of the other product (e.g., washing product is used for clothing). In practice, different amounts of final and non-final products can still be added, e.g., because of the linearity, under the condition that related final product amounts do not transcend their global demand. Otherwise, double counting occurs. See Table 2 for an example. Considering only final products will help to easily avoid this issue and in case of non-final products, low amounts will most likely not create an issue, making the need for an additivity check less likely. Weidema et al. [74] mention that this additivity is "hypothetical in the sense that it requires the unrealistic steady-state assumption that all product impacts take place at the same point in time". Given the consideration of time in Section 3.2, it is not the case that product impacts should take place at the same time in ALCA. Mathematical functions can also be added for that matter.

Table 2. Fictional example of the ALCA validity check for additivity of a final and a related non-final product, in this case clothing and washing product. Besides the mentioned evaluation examples, if a washing product amount higher than 25 or a clothing usage bigger than 5000 is intended to be considered, this cannot be eligible within the framework of ALCA, unless an alternative extrapolated version of the world is considered.

\begin{tabular}{|c|c|c|c|}
\hline & \multirow[b]{2}{*}{ Global Amount (Fixed) } & \multicolumn{2}{|c|}{$\begin{array}{l}\text { Example in Which Final and Non-Final Products Are } \\
\text { Intended to Be Both Considered and Thus Their ALCA } \\
\text { Results Added }\end{array}$} \\
\hline & & Example 1 & Example 2 \\
\hline $\begin{array}{l}\text { Amount of Washing product } \\
\text { (non-final product) }\end{array}$ & $\begin{array}{l}25 \text { (used for clothing at } 0.005 \mathrm{~L} \\
\text { per clothing usage, i.e., } \\
200 \text { clothing per L) }\end{array}$ & $\begin{array}{l}1 \mathrm{~L} \text { of washing product: } \\
\text { implies } 200 \text { clothing usage }\end{array}$ & $\begin{array}{l}10 \text { L of washing product: } \\
\text { implies } 2000 \text { clothing usages }\end{array}$ \\
\hline $\begin{array}{l}\text { Amount of clothing usage } \\
\text { (final product) }\end{array}$ & 5000 usages of clothing & 4500 usages of clothing & 3500 usages of clothing \\
\hline $\begin{array}{l}\text { Recalculated final product of } \\
\text { clothing usage amount }\end{array}$ & & $200+4500=4700(<5000)$ & $2000+3500=5500(>5000)$ \\
\hline Evaluation & & $\begin{array}{l}\text { Ok for ALCA; no } \\
\text { double-counting }\end{array}$ & $\begin{array}{c}\text { not ok for ALCA: } \\
\text { double-counting, unless an } \\
\text { extrapolated world is } \\
\text { considered (with } 5500 \text { clothing } \\
\text { usages as final products) }\end{array}$ \\
\hline
\end{tabular}

However, this limitation to global final product amounts, is only obligatory if you want to study that particular version of the Earth for which those final product amounts hold. One can thus still use greater amounts, but then an alternative "extrapolated" version of the Earth is studied, extrapolated to meet those additional final product amounts. At best, for that extrapolated Earth, its impact is first modelled, and within that context an ALCA is then applied. 
Concerning modelling being restricted by additivity (e.g., guaranteed through linearity), this does not only reside in the modelling of the industrial chain but also environmental impact. If this theoretical additivity prerequisite would be discarded then the portions of environmental impact would overlap (the sum would not equal the total). In practice, linear factors called characterization factors are used that represent the normalized ratio of the effect per resource or emission flow (see Section 3.7). Maybe the scientific community could consider uplifting this theoretical additivity as a prerequisite for ALCA, but it would lead to another degree of freedom in the model that could undo the normative nature of ALCA.

Regarding CLCA, In the UNEP-SETAC [31] definitions and report, there is no constraint at all about the types of model for CLCA and the main idea is to, as best as possible, represent consequential relationships. In practice, the integration of various models and/or consideration of non-linear models are brought forward [5,50,75-77]. Yet, a linear model can still serve as an approximation, as done for the consequential database in ecoinvent 3 or higher [54]. See Appendix A.2 for an explanation on this. A delineation of consequential models as linear models, as done by Weidema et al. [78] ("Consequential models are steadystate, linear, homogeneous models, with each unit process fixed at a specific point in time"), is thus a too narrow modelling specification than what is restricted by the UNEP-SETAC [31] definition of CLCA. Rajagopal [34] presents a mathematical framework in the context of CLCA for economic modelling. Although this might be an interesting practical framework, it cannot be argued as the single valid one because of the mathematically open modelling nature of CLCA at a conceptual level.

Overall, purely based on the concepts, ALCA modelling should be additive (e.g., linear), with an extra check on double-counting, and CLCA modelling has no restriction in this respect.

\subsection{How Multifunctionality Is Dealt With}

A particular issue to assign an impact to a product or related decision occurs when considering processes or parts of product systems that create multiple outputs. For example, when burning biogas in a co-generation unit, this creates both electricity and heat. Even though either can be wasted, let's consider here that both are used, which implies a multifunctionality issue. Another example would be that when valorizing waste of product A into product B, the product system would thus create two products. This is in fact not a pure conceptual/theoretical issue, as it only is present because of the existence of multifunctional processes. Yet, it is hard to even consider a world without any multifunctional process and thus it has become a general systematic issue of concern. The multifunctionality issue does not only relate to the functions of product flows but also the function of waste treatment [79]. See also the work of Schaubroeck et al. [80] for a broader overview, including a coverage of waste valorization as multifunctionality issue. Please keep in mind, as mentioned in the introduction, we do not focus on the societal relevance of ALCA or CLCA, nor that of their methods to address this multifunctionality issue. We also only introduce some prominent existing approaches to deal with multifunctionality. A first general solution, regardless of ALCA and CLCA, to addressing the multifunctionality issue, is to prevent it by subdividing the process into separate processes that belong to each separate functionality, as according to ISO 14044, but this cannot always be done.

In ALCA, the idea is to attribute a share of the global environmental impact to a specific product system with a certain functionality (see Table 1). To do so, one in fact may need to artificially split the human/industrial system into different product systems, and related processes, because these are interlinked. The issue of multifunctionality is commonly resolved using normative rules of partitioning in ALCA [51,81]. In the case of biogas burning in a cogeneration unit, the environmental impact of biogas burning and each linked process needs to be partitioned between the product system of the particular electricity as functionality and a system with the particular heat as functionality, if it is desired to consider the impact of these products produced through the same process 
separately. See Figure 6. Such partitioning could be based on the energy content of the produced electricity and heat. This partitioning means that the biogas process is artificially split into two, which is unrealistic since in reality the delivery of both heat and electricity will take place together for that particular cogeneration process. If biogas is burned, both electricity and heat will be cogenerated within a cogeneration unit. ALCA results are not representative of reality, if this partitioning is applied, which is practically commonly unavoidable. Moreover, only one partitioning key can be selected (e.g., energy, mass or price or a certain rule), which implies that balances for other characteristics cannot be preserved [53,82]. For example, if we partition the inflow of wood (with $x$ carbon content) to saw dust and sawn wood for a multifunctional sawing process based on their prices, it may be that the amount of wood (with a certain carbon content) assigned to saw dust is different from the actual mass and carbon content of the saw dust. However, as already mentioned in Section 2.1, a concept does not need to be guaranteed realistic to be acceptable. An alternative to this situation in ALCA is the expansion of the functionality and thus also expand the product system to consider the aggregated product system, as brought forward in ISO 14040-14044:2006, called "system expansion". For example, in the case of biogas burning with cogeneration, consider both respective amounts of "electricity and heat" as functional unit and thus consider the biogas process as a whole, without splitting it. However, because of the interconnectivity of the earth, you can easily end up considering numerous amounts of products and your product system will approach the complete globe. Moreover, system expansion would imply that you cannot really compare single products if they are coproducts (as you cannot single out the impact for each one). Partitioning based on an allocation key is then also commonly applied in life cycle inventory databases. One needs to take into account this particular type of abstraction when interpreting ALCA results. This is besides the abstraction by only considering additivity-restricted modelling as mentioned in Section 3.4. Moreover, this partitioning aspect is also considered besides the cut-off approach and APOS approach that define the product system boundary differently (see Section 3.1).

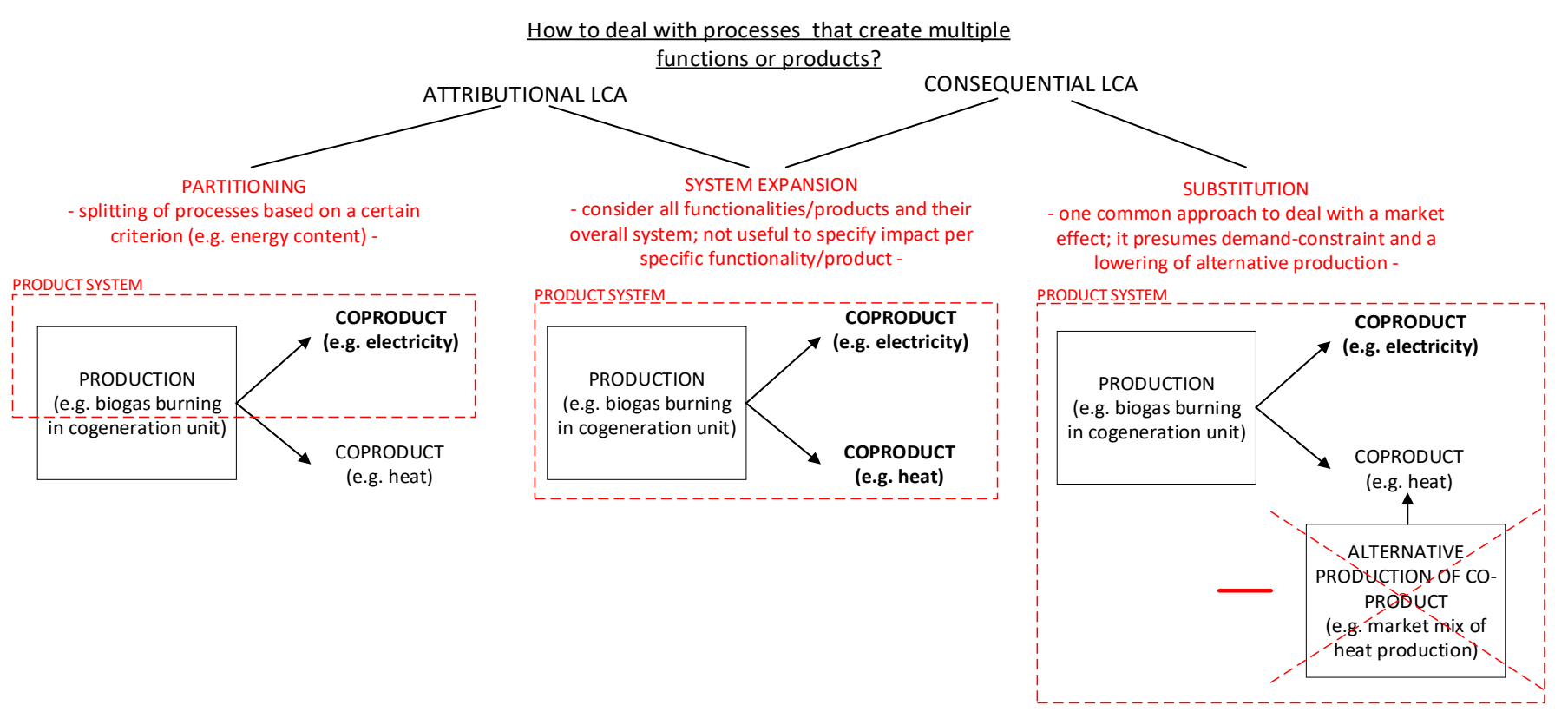

Figure 6. Three prominent different ways of how multifunctionality issue is dealt with and whether they associated with ALCA and CLCA, based on literature [51,81]. Schrijvers et al. (2016) already pointed out that "system expansion" is valid for both ALCA and CLCA. For CLCA, only one common approach is presented ("substitution") but in fact there are many others based on market or other modelling. These are just three approaches and others exist.

In other words, there can be APOS or cut-off with any kind of partitioning key. Finally, both partitioning, as pointed out by Majeau-Bettez et al. [83] and system expansion (when 
avoiding double counting of final products, in Section 3.4), as brought forward here, respect the production balance, implying that they also respect the additivity requirement. See Section 3.4. Majeau-Bettez et al. [83] also present other approaches to deal with multifunctionality for which the production balance and additivity requirement would not be met.

In CLCA, the goal is to model as realistically as possible the cause-effect chain starting with the decision (see Table 1). "The boundaries of the system are expanded so as to include those processes which are affected by the consequences of the decision at hand. In doing so, the resulting functionality of the whole system would consist of multiple functions, including the main system and those added by the processes included in the boundaries." [7]. An example of multifunctionality is that "electricity from biogas burning in cogeneration" is demanded, that will indirectly imply the production of heat as well. (Note again that in this example we presume that the heat is valorized and not wasted, which commonly happens with heat from cogeneration). For CLCA, it is also possible to apply an expansion of the functional unit so that the total respective system is considered, commonly referred to as "system expansion", e.g., both consider heat and electricity produced as functionality and the totality of the entire system related with the cogeneration unit. When only wanting to consider the product system and environmental impact for the electricity, the question is then how to deal with the produced heat. From a consequential perspective, it is essential to consider how the market will react to that extra amount of product, in this case the heat. CLCA are then often also linked with market or other consequential models $[23,25,56]$. Based on a simple assumption, the market is demand constrained, one can presume that there will be less alternative production of heat. If $\mathrm{x} \mathrm{MJ}$ of heat is created through biogas cogeneration then the alternative production of heat (mix of natural gas burning, heat pump etc.) is lowered with $\mathrm{x}$ MJ of heat. This approach is called the "avoided burden" or "substitution" approach $[51,81]$. This leads to a simple but limited solution of the multifunctionality issue in case of CLCA (see Figure 6). Keep in mind that the substitution approach is different from system expansion [57]. It is imperative to realize that this "substitution" or "avoided burden" approach only represents one way of how the market will react and is not a main characteristic of CLCA in general as it is not restricted by its definition (Table 1). It will depend on the case if it is the most appropriate approach. It is however a commonly applied approach as it is used in the consequential system model of an LCA inventory database [54,55]. One could also regard this substitution approach as a comparison of scenarios; a comparison between a scenario with an extra demand of a certain product and one reference scenario without it (but both with the same market demand for the generated coproducts). It is important to note that the consequential version of that particular database encompasses more than just this substitution solution for multifunctionality, but it still remains just one modelling framework. Alternatively, the market could also be supply-constrained and consume the co-product additionally. In the latter case, the consequential benefit of consumption or product benefit needs to be considered $[50,84]$. It is thus important to consider that the choice for the substitution method is a modelling parameter and not a restriction related to the CLCA concept. To have a better idea on how a different solution may affect the outcome considerably, keeping in mind their difference in goal, you can consult elaborative case studies in following literature [85-87]. Focusing on a specific case of linerboard recycling, a recent study [80] shows that the water scarcity impact is lower for recycling than for virgin cardboard in case of attributional LCA, but it is vice versa in case of consequential LCA. In case of capital goods, specific apprehended solutions for the multifunctionality issue are discussed by Schaubroeck et al. [36].

In hindsight, the ISO 14044 also provides a hierarchy of solutions to deal with multifunctionality, but it does not link these with either the ALCA or CLCA concept, which it also does not mention. A first solution, would be to subdivide the process as yet mentioned, but this is rather a prevention than a solution. If that does not work, system expansion is advised and subsequently partitioning, with a priority for a partitioning key based on a physical attribute. Yet, this hierarchy is questionable, as (1) alternatives such as substitution 
are not clearly mentioned (even though some questionably link it with the text concerning system expansion or economic partitioning [31,57]), (2) system expansion provides another expanded functional unit, which implies it is a different solution rather than a better solution, and (3) it is impossible to argue in favor of a superior partitioning key, as each has its advantages, and (4), more in general, the choice of solution is dependent on the specific Goal \& Scope of the study, which can relate with ALCA or CLCA. It would be advised not to follow the ISO 14044 hierarchy, and we advise to reconsider the respective section in the revision of ISO 14044, which is ongoing. Schrijvers et al. [57] also question the ISO hierarchy and Moretti et al. [88] highlight as well its ambiguity in interpretation and application through their meta-analysis. (The recent 2020 amendment of ISO 14044 defines "System expansion avoids allocation by integrating a functionally equivalent product system, that is assumed to be substituted by the co-product (product B), within the system boundary". However, then system expansion would only be equal to avoided burden or substitution, losing the conceptual idea of expanding the functional unit and the system. There are moreover also other theoretical ways to address the effect of co-products in consequential LCA such as product benefit characterization [80].)

To conclude, this multifunctionality issue has originally been prominently at the core of ALCA-versus-CLCA debate, but the difference between these approaches is clearly larger than that, as Zamagni et al. [7] also note. Although this issue of multifunctionality is a pragmatic one, occurrence of these is quite omnipresent. To obtain an impact per function and related product amount, partitioning needs to be applied in ALCA and in CLCA the consequential effect of the coproduct needs to be considered, based on the respective concepts. In specific ALCA and CLCA modelling frameworks further parameters or choices should be specified and argued concerning which partitioning key in case of ALCA and how the consequential effect is going to be modelled in case of CLCA.

\subsubsection{Environmental Multi-Input Processes and How to Deal with This}

Similar to the multifunctionality of human/industrial systems, there can also be environmental processes that have multiple environmental pressures as input. Figure 7 illustrates this with an example on smog creation having both $\mathrm{NO}_{\mathrm{x}}$ and volatile organic compounds (VOC) as inputs, which is a well-studied process [89].

Following the additivity requirement of ALCA to the letter, within life cycle impact assessment, the respective process should be partitioned among both these flows if they are (indirectly) from human/industrial origin. Only in the latter case, will the sum of the ALCA of all final products lead to the global environmental impact, as required by the definition (see Table 1). However, in practice, this partitioning is not done and instead the process is run presuming that the input of the other is defined by a background concentration level of the reference environment (see Section 3.3), the ceteris paribus principle [90]. Furthermore, this rule is not a common model choice but almost presumed as a conceptual rule, which seems in theory in contradiction with the rule of additivity in ALCA. This may be interpreted as a consideration of a background reference environment without the product system, but it excludes the fact that the reference environment is also partially induced by product systems and their flows (e.g., VOC emissions from industry), which is specifically relevant for large amounts (see Section 3.3). Environmental processes can thus be the result of two product systems (e.g., $\mathrm{NO}_{\mathrm{x}}$ and VOC originate both from human/industrial processes), which in theory necessitates the need for partitioning these. A thorough reconsideration of life cycle impact assessment for ALCA seems needed in practice in which there is also partitioning of environmental processes that use different flows of the industry to be consistent with the UNEP-SETAC [31] definition. 


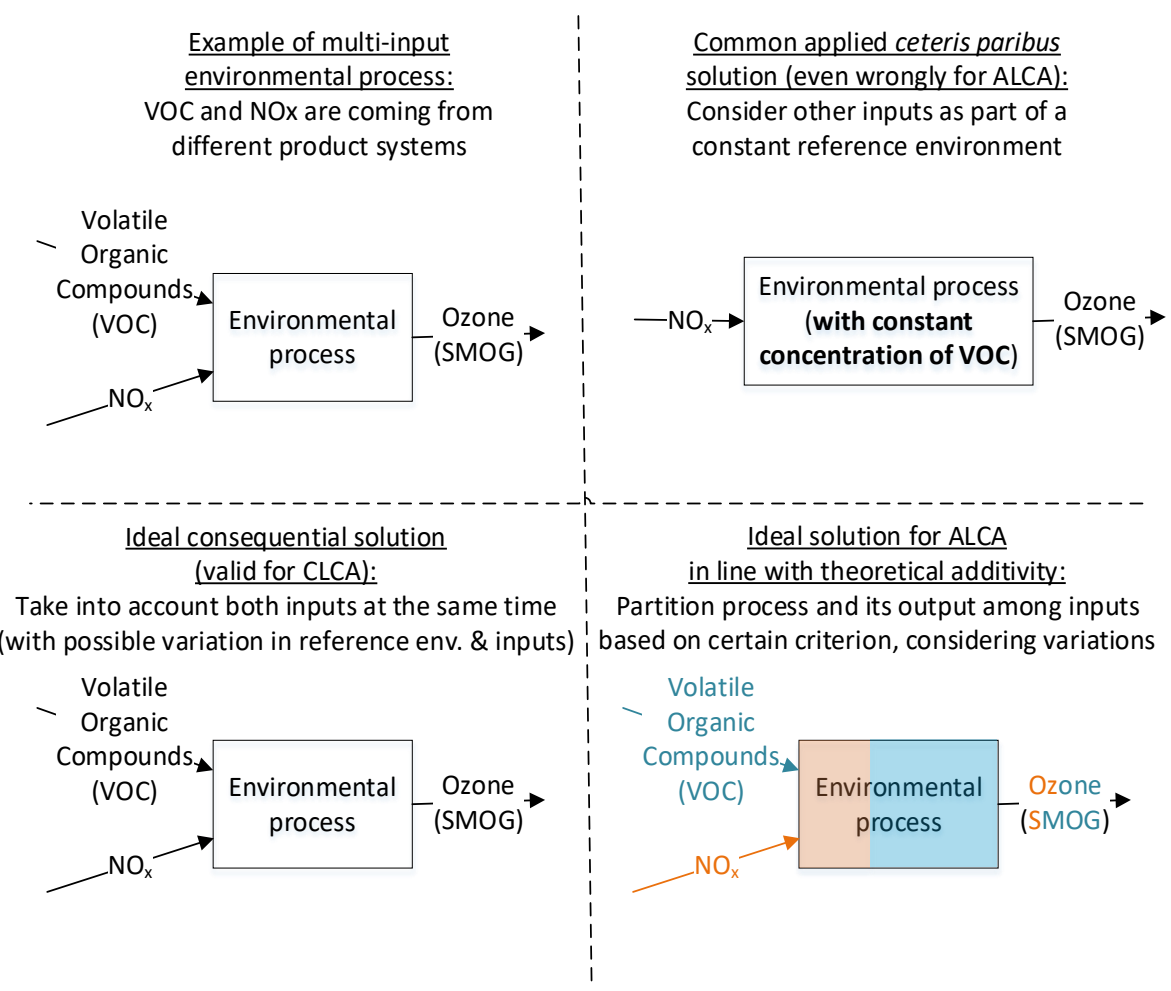

Figure 7. Multi-input processes and how they are and should be dealt with in attributional and consequential LCA.

\subsection{Marginal versus Average Considerations}

CLCA considers the changes that are induced by a decision in a uniquely consequential manner and ALCA considers attributing a share of global impacts (see Table 1). This distinction reflects a specification for so called consequential processes (related with a change in the world due to the decision) in the case for CLCA and interlinked processes (related through interlinkage based on physical/energy flows and services, within a world not changed by the product amount) for ALCA. The suppliers, i.e., the type of processes (e.g., renewable electricity suppliers), as reviewed and discussed by Ekvall and Weidema [43], are specified as "marginal" for CLCA and "average" for ALCA. The choice of the wording "average" may be confusing, since it does not strictly relate with the above meaning, but rather with an average for a studied group of products, possibly of the same type, or its product system and effect. When it comes to marginal, various definitions of this word exist, as presented in Table 3.

Table 3. Various definitions of the word "marginal".

\begin{tabular}{cc}
\hline Type of Definition & Definition \\
\hline Marginal (small) & "very small in amount or effect" [91] \\
\hline Marginal (change) & "In [economics], marginal concepts are associated with a \\
& specific change in the quantity used of a good or service" [92] \\
\hline Marginal (small change) & "relating to or resulting from small or unit changes" [93] \\
\hline
\end{tabular}

Marginal can be used for CLCA, when considering the definition of marginal associated with a change in amount of products due to a certain decision, denoted as "marginal (change)". However, there is also the common definition of the word marginal: "very small in amount or effect", as presented in the Cambridge English Online Dictionary [91]. This definition we call "marginal (small)" and we will utilize this definition in our work. Moreover, there is the definition of marginal that relates to small change, as shown in 
Table 3, which we refer to as "marginal (small change)". In latter two cases, the use of the word "marginal" is not uniquely linked with CLCA. There is no specifications of certain amounts of certain set of products or effects in the definitions. Overall, the definitions in Table 1 of ALCA and CLCA make no specification towards average and marginal (small or small change) respectively, nor can it be unequivocally inferred from them. To avoid further confusion, in the case of suppliers, we resort to use "consequential" and "attributional" suppliers as wording, which relate entirely with the CLCA and ALCA concepts, respectively. Note that the use of the word "supplier" may thus also be questioned because a consequential supplier is not supplying to the process that induced it. A more correct wording would be "type of process" instead of "supplier". Yet, we stick with the wording "supplier" out of convention.

In ALCA, the attributional suppliers, are thus the type of processes which are interlinked through a physical/energy or service flow, i.e., the actual suppliers as mentioned in UNEP-SETAC [31]. For the example of $1 \mathrm{kWh}$ of electricity of a reference scenario (not an extra demand), the interlinked electricity suppliers of that reference scenario are the ones that have actually produced that specific used $1 \mathrm{kWh}$. However, if the average product life cycle on the market is considered, only then the interlinked suppliers will be the average suppliers on the market.

In CLCA, the idea is to model the affected suppliers and technologies, i.e., the consequential ones, which are not necessarily the ones that are interlinked (based on physi$\mathrm{cal} /$ energy flows or services) since the overall change in the world is considered, not the changes of the interlinked suppliers of the demand. For example, if one more $\mathrm{kWh}$ of electricity is demanded, the market will respond by increasing a certain set of electricity production alternatives, but the consumed electricity may still have been produced by other suppliers. Consequential suppliers are the ones that respond to a change in demand, not the ones that necessarily provide the demand, i.e., attributional suppliers. The identification of the suppliers is part of the modelling in CLCA, and has been researched by many scientists $[43,94,95]$. What that set of consequential suppliers will be, will depend on the market response. It may be just a single technology (e.g., nuclear energy) but it could as well be the current average market mix. This could be specifically the case if the decision is small. For example, if a low extra amount of electricity is considered, then maybe the current average electricity production plant can respond to that demand by increasing their production (if the maximum production capacity has not been met). However, this should not be seen as a fixed or general rule, as the ILCD report of the JRC-IES [28] proposes, and rather as a case dependent issue covered by the modelling [26]. Scale should after all not influence the choice of the approach from a conceptual viewpoint, but it can influence choices in practical development of a modelling framework.

The notions of marginal (small) and average can be relevant when it comes to specificity of product/decision and related product system and effect propagation. Albeit this is more a matter of the modelling framework and the specificity of the study, we clarify matters here shortly to shed some light on this aspect. It can be specified whether a marginal (small) or average decision or product is of concern. For example, if a machine can wash 1000 apples maximum, an extra machine will be used or needed for the 1001th apple. If the goal is to assess the impact of the 1001th apple, then the complete production and complete operation of a machine, used for that single apple, should be considered. If instead the average apple is considered of all the 1001 apples, then the average impact should be regarded (i.e., dividing the impacts of two machines by 1001), not that of a particular apple. This specification of an average or marginal (small) product or decision is part of the scope, independently whether ALCA or CLCA is considered, and should not be confused with the consideration of attributional or consequential suppliers above. Although the above example of a single apple associated with an extra machine usage is not that presumptuous, it could also be another amount of apples lower than 1000.

A common misconception, as Boulay et al. [96] point out, is the association of the marginal (small) or average derivation of characterization factors (CF) (that cover the im- 
pact; e.g., $299 \mathrm{~kg} \mathrm{CO}$-equivalents per $\mathrm{kg} \mathrm{N} \mathrm{N}_{2} \mathrm{O}$ ) with either attributional or consequential LCA. As well explained in their work, the environmental response can be quite non-linear which makes it a challenge to derive a linear factor (in particular interesting for ALCA but only an option for CLCA). Forin et al. [97] makes a more clear distinction between the average effect for an amount range, which is over a range regardless of the inventory (e.g., effect of 10 to $100 \mathrm{~kg} \mathrm{CO}$ emitted), i.e., average $\mathrm{CF}$, and the "incremental" effect of a specific amount, i.e., incremental CF. Yet, we do not use the terminology incremental but just "amount-specific" as it relates with what is actually covered (e.g., effect of a specific amount of $\mathrm{CO}_{2}$ emitted starting from actual levels).

Note that for average CF, our definitions are slightly different from Forin et al. [97] as we do not consider the average CF to necessarily start from 0 (i.e., for all amounts) but this can be just of a segment. Moreover it would be possibly impractical to always trace back to 0 . In this sense it might be good to distinguish between such segmented average $\mathrm{CF}$ and total average CF, the latter starting from 0 . Nevertheless, average CF imply a value-laden equity distribution of effect among elementary flow amounts [97,98], which makes it theoretically not the best choice for consequential impact consideration.

"Marginal" (small) effects and CF can be seen as a special case, as it is conventionally interpreted as being for a negligibly small increase to a certain background concentration presuming it does not alter the latter, i.e., the CF is the slope at the background level. This follows as well the ceteris paribus principle [90], which is theoretically not recommended (as any elementary flow amount will cause a change in its level), but just a practical approximation for ease of use in case of small amounts. Heijungs [98] exemplifies the goodness of approximation by a marginal CF approach for small amounts, even when faced with multi-input environmental processes (as discussed in Section 3.5.1), which implies that it may be a practical solution to avoid the partitioning issue.

In the case of LCIA, following its consequential viewpoint (see Section 3.7), the only correct theoretical approach is the amount-specific approach. This implies that for each amount a separate CF value needs to be specified, thus having not a general CF factor, making it one of the factors of its impracticality. Average and marginal (small amounts) CF approaches can be seen as alternative practical approximations. The appropriate choice of either an average, amount-specific or marginal (small) CF approach is thus more related with the practical context (e.g., quantity of intervention [96]). For example, when focusing on the inventory amount, consider the final impact in function of an emission amount to be sigmoidal (S-shaped). In that case for very large or small amounts (at the complete flat ends of the S-shape), a consideration of the slope of the average linear part of the S-curve as impact factor, will give an estimation that is more off, and a marginal consideration is more fitting. Yet, if we consider an amount that is part of the linear part, the average slope of the linear part will present an adequate estimation. Finally, as already pointed out by said authors, results will only for sure be additive, thus complying with the additivity criterion of ALCA in case of marginal or average, if either always marginal or always average characterization factors are considered, not a mix of both. Yet, an extra aspect for ALCA to guarantee additivity is that in case of dependency for non-linear effects (i.e., the effect of the elementary flow amount is influenced by another amount, i.e., a certain amount will have a different effect based on presence of other elementary flow amounts), the average and amount-specific CF need to be derived altogether or a sequentialization is needed guarantee additivity. For amount-specific CF, an objective approach can be based on the sequence of "user" [97], which is interpretable as the sequence of elementary flow amount (i.e., the first elementary flow amount will induce the first part of the effect across the impact curve). For independent effects, i.e., local effects in separate systems (e.g., toxic effects in separate lakes), this is not needed (see Table 4 for an overview on this section).

Overall, there is no strict delimitation of average to ALCA or marginal (small) to CLCA. In practice, average datasets can be used to approximate marginal ones, under a presumption, but this is a modelling rule/choice not a conceptual rule. For example, for background processes in the inventory, average datasets can be used. 
Table 4. A summary of the consideration of average or marginal aspects from a conceptual viewpoint in case of ALCA and CLCA. Marginal implies small in this table.

\begin{tabular}{lll}
\hline & \multicolumn{1}{c}{ ALCA } & \multicolumn{1}{c}{ CLCA } \\
\hline $\begin{array}{l}\text { LCIA Dataset (e.g., the amount of } \\
\text { additional global warming induced) }\end{array}$ & $\begin{array}{l}\text { ideally amount-specific, but in practice } \\
\text { marginal or average CF are both possible. } \\
\text { This needs to be specified (but should be } \\
\text { consistently one of the two) }\end{array}$ & $\begin{array}{l}\text { ideally amount-specific, but in practice } \\
\text { marginal or average CF are both possible. } \\
\text { This needs to be specified }\end{array}$ \\
\hline $\begin{array}{l}\text { Supplier-special case of effect, focusing } \\
\text { on suppliers of products/services }\end{array}$ & $\begin{array}{l}\text { Interlinked suppliers are considered that } \\
\text { have provided the product or service } \\
\text { during the product life cycle (e.g., electricity } \\
\text { mix over period of consumption) }\end{array}$ & $\begin{array}{l}\text { The consequential suppliers that is/are } \\
\text { induced by the decision at the global } \\
\text { level should be considered, which are not } \\
\text { necessarily the interlinked ones (e.g., new } \\
\text { supplier that will meet the extra amount } \\
\text { of electricity demanded) }\end{array}$ \\
\hline $\begin{array}{l}\text { Decision or Product life cycle (e.g., } \\
\text { impact of one specific marginal apple } \\
\text { amount or average of the global market) }\end{array}$ & $\begin{array}{l}\text { It can be marginal or average amounts. } \\
\text { This needs to be specified }\end{array}$ & $\begin{array}{l}\text { It can be marginal or average amounts. } \\
\text { This needs to be specified }\end{array}$ \\
\hline
\end{tabular}

\subsection{Complete Framing of Environmental Impact Assessment Coupled with the Product System}

When it comes to life cycle impact assessment (LCIA), the characterization of the environmental impact of the product system, there is no exact definition brought forward solely for ALCA, nor solely for CLCA by the UNEP-SETAC [31] or any source that we have knowledge of. This is, to the contrary, the case for the concept of product system. As is the case in the UNEP-SETAC [31] report, "attributional" and "consequential" is mainly associated with the product system, and thus the life cycle inventory. In practice, the same LCIA methods are used in both ALCA and CLCA studies. In both cases, LCIA is regarded as based on characterization models that follow environmental mechanisms [9], i.e., LCIA is consequential in nature in the sense that it covers cause-effect relationships behind these mechanism. This is stressed by following text sections in the ISO 14044; concerning stating the environmental relevance is mentioned "the ability of the category indicator to reflect the consequences of the LCI results on the category endpoint(s)" \& "LCA addresses the environmental aspects and potential environmental impacts (e.g., use of resources and environmental consequences of releases)". LCIA has no rule on interlinkage as done for the product system in ALCA, which is discussed in Section 3.1. If it would be similarly the case, all interlinked environmental processes going back to the creation of the universe should be for sure considered. For example, for the extraction of oil, we should then also consider the processes that generate the oil, and eventually the preceding creation of the atoms ( $\mathrm{C}, \mathrm{H}$ etc.) that constitute it, etc., and not just the processes that are a consequence of the oil extraction. Yet, in ALCA, only the product life cycle in the industry is considered, not necessarily that in the entire environment. Also for ALCA, the LCIA characterization is thus consequential.

In the characterization of these environmental mechanisms, indicators are used and a distinction is made between indicators that assess the impact midway the cause-effect chain (e.g., global warming potential expressed in $\mathrm{kg} \mathrm{CO}_{2}$ equivalents) and those that assess the impact at the endpoint, i.e., on the Area of Protection (AoP) (e.g., DALY; i.e., loss in healthy life years, as endpoint indicator for damage to human health) $[99,100]$. As mentioned by Schaubroeck and Rugani [50]: "Ideally, without considering practical limitations, endpoint indicators should be preferred, as these cover the complete cause-effect chain up to the AoPs. However, in practice, midpoint indicators are often considered or advised instead of endpoint indicators due to the higher reliability and availability of data and models." [100]. The most basic set of midpoint indicators, which we call here "inventory indicators", just presents the elementary flows as such (e.g., amount of extracted water, amount of land occupation), which for resources have been for example named resource accounting methods as specified in literature [101]. In other words, they are at the very beginning of the cause-effect chain. Overall, except for the latter "inventory indicators" (both emissions and resources), all impact indicators 
already cover a propagation of consequential effects and are thus purely consequential in nature. Only the inventory indicators (representing elementary flow amounts) could also be regarded as non-consequential in nature and as accounting indicators, in line with ALCA thinking. In other words, if it is the desire to have a solely accounting-based approach, an ALCA study should be performed with such inventory indicators for the LCIA phase.

Keep in mind that the consequential nature of LCIA also implies that the impact may also be infinite over time and in quantity, similar to that of a product system (see Section 3.1.2), although similarly in practice finite numbers are obtained because of practical restrictions or cut-offs (e.g., 100 years for global warming potential). Some impact methods though only cover a certain extent of the cause-effect chain and/or normalize it with impact of other compounds. However, the different concepts of ALCA and CLCA do cover the environmental impact, as shown in the first column of Table 1 . This translates in a necessity to distinguish attributional from consequential LCIA, when not only considering inventory indicators as explained above.

For CLCA, the concept behind the product system (characterized by the LCI) and environmental impact propagation (LICA) is the same, namely consequential propagation. Hence, these can be completely integrated and there is no need for a distinction between these from a conceptual viewpoint. In practice, an integrated model can be developed consisting of the complete interaction of the human/industrial and environmental system, reflecting reality, without mathematical constraints (see Figure 8).

ATTRIBUTIONAL LCA

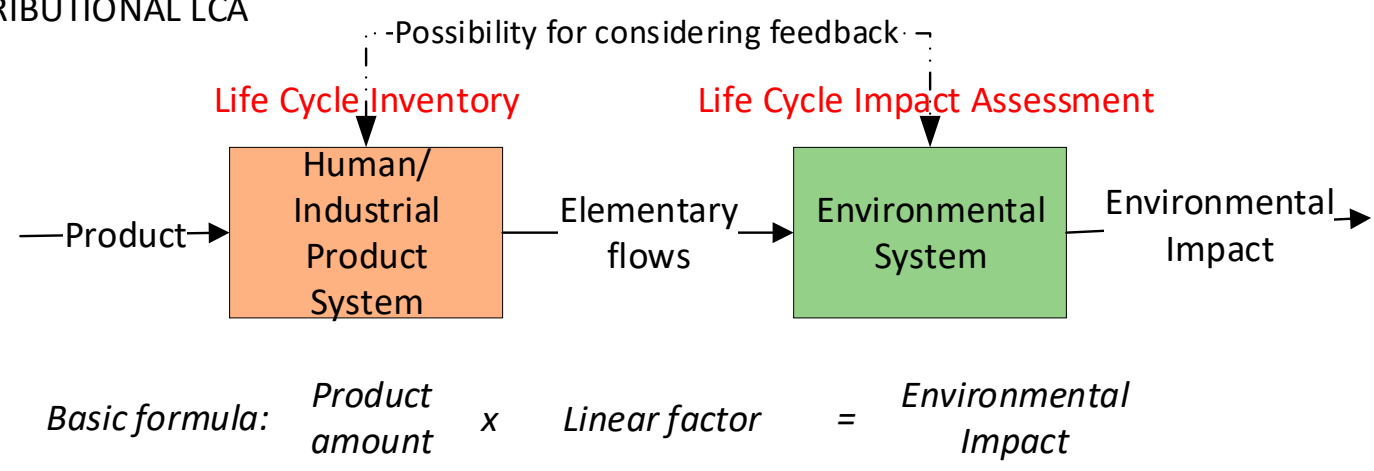

\section{CONSEQUENTIAL LCA}

Life Cycle Inventory \& impact assessment could be fully integrated

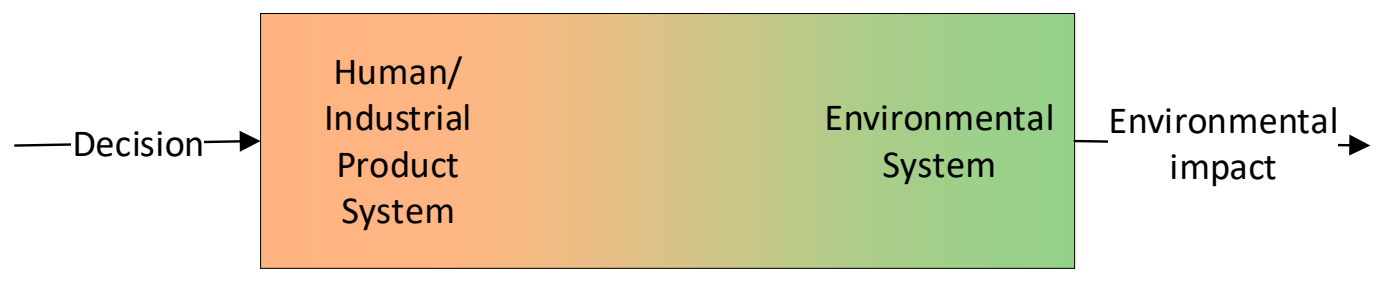

Basicformula: $\quad$ Function(decision) $=\begin{gathered}\text { Environmental } \\ \text { Impact }\end{gathered}$

Figure 8. Mathematical model representation as delimited by the concepts of Life cycle inventory and Life cycle impact assessment in the context of attributional and consequential LCA. The figure shows that for ALCA, the life cycle inventory and life cycle impact assessment need to be regarded separately as they have a different conceptual nature and rules, which is not the case for CLCA (everything is consequential). For ALCA the modelling framework is restricted because of additivity and we here present the linear approach, which is the most straightforward one to achieve that. Please keep into account definition of environment as discussed in Section 2. 
For ALCA, a first conceptual aspect that pops up is that LCIA is initially purely consequential, while ALCA and its concept of product system are considerably normative, i.e., considerably defined by rules. In addition to defining the product system, there are rules that restrict ALCA more. More precisely, there is the theoretical additivity as discussed in Section 3.5 and how a "portion of global burden" is defined.

When it comes to modelling rules for LCIA of ALCA, as already mentioned in sections in this article, there are certain aspects that serve as rules or restrictions for the Attributional LCIA.

In particular, these are the following for attributional LCIA:

(1). restricted modelling, e.g., linear, based on the additivity requirement (see Section 3.4).

(2). should not exceed total, based on the additivity requirement (see Section 3.4).

(3). For environmental multi-input processes, partitioning should be applied with multiple inputs originating from human/industrial system, based on the additivity requirement (see Section 3.5.1).

Although current LCIA methods do not follow the third rule in practice, they should do so to guarantee their alignment with the definition of ALCA of UNEP-SETAC [31]. Given the difference in nature between LCI and LCIA for ALCA, a distinction between both in practice is needed (i.e., specifying whether a process belongs to LCI or LCIA), which boils down to drawing a line between the human/industrial product system and environmental system (as defined in Section 2). This all results in an overall restricted modelling approach as presented in Figure 8. For CLCA, a full integration of LCI and LCIA is possible. Please see the Appendix A.2 for a more concrete mathematical formulation, with focus on linear simplification for CLCA.

Feedback loops are possible both in case of ALCA and CLCA. Weidema et al. [12] have discussed an advanced linear model in which the economy and environment are interlinked, with feedback loops. However, in the field of LCA, very similar models and their limitations have yet been brought forward in literature [14,15]. For ALCA, it might be interesting to consider such an integrated framework especially for large quantities that change the background system (see Section 3.3). However, the different rules between LCI and LCIA should be kept into account. For CLCA, it is still interesting but the framework of Weidema et al. [12] is limited to linear effects while existing non-linear effects should at best be covered, especially in CLCA, through non-linear models with feedback loops.

\subsection{Overview of Aspects}

Table 5 presents an overview of all the aspects and how these are addressed by ALCA and CLCA, following the argued definitions of UNEP-SETAC [31] to the letter.

\subsection{Compliance of ALCA and CLCA with ISO 14040-14044}

As yet mentioned, in this article we do not focus on the relevance of ALCA and CLCA, and will thus also not present any reflection on the relevance of adapting ISO 14040-14044 (hereafter referred to as "ISO standards"). We only present what the compliance of ALCA and CLCA is and what the adaptations should be for ISO-compliance, from a theoretical perspective. Since a revision is ongoing, at the moment of writing, it means that the ISO can be changed and these comments could support that endeavor. 
Table 5. Overview of the covered aspects and how they are differently addressed by attributional (ALCA) \& consequential (CLCA) life cycle assessment, following the definitions of UNEP-SETAC [31] to the letter.

\begin{tabular}{lll}
\hline & \multicolumn{1}{c}{ ALCA } & \multicolumn{1}{c}{ CLCA } \\
\hline $\begin{array}{l}\text { Basic concept/Relation with global burden } \\
\text { (Section 2.2) }\end{array}$ & $\begin{array}{l}\text { Share of the global impact linked with a } \\
\text { product life cycle. }\end{array}$ & $\begin{array}{l}\text { Change in global impact induced by a decision } \\
\text { and its consequences. }\end{array}$ \\
\hline
\end{tabular}

$\begin{array}{ll} & \begin{array}{l}\text { All processes have interlinked relationships } \\ \text { based on physical, energy and service flows, }\end{array} \\ \text { Relationships and boundaries of the product } & \text { constituting the product life cycle, which is }\end{array}$ system, of which the impact is assessed (Section 3.1)

The aspect of time (Section 3.2)

Specify product system and its impact separately or in scenarios (Section 3.3)

Constraints in mathematical modelling due to theoretical concept (Section 3.4)

How multifunctionality is dealt with (Section 3.5)

Marginal versus average considerations in the assessment (Section 3.6) assessment, coupled with product system (Section 3.7) constituting the product life cycle, which is also the product system.

The product system can be infinite, and propagated amount as well.

Absolutely: processes can be considered in past, present or future.

Relatively: considers processes also before product finalization, i.e., relative past consideration.

\section{Can be both:}

Separately: share of human/industrial system and its global impact.

Scenario: difference between world and a hypothetical world without product system and its impact.

restricted by additivity (e.g., guaranteed by linearity), necessitating a validity check or consideration of extrapolated world.

Needs to be done through partitioning processes, both for LCI and, in case of environmental multi-input processes, for LCIA. An alternative is system expansion.

Interlinked suppliers need to be considered. Amount-specific effects is advised but in practice average or marginal impact effects are possible and should be consistently considered. Average or marginal product consideration is possible.

Environmental impact assessment is purely consequential (with exception of inventory indicators), but limited by additivity, e.g., necessitating partitioning. This all, necessitates a separate consideration from the product system, due to these other rules.
The induced processes (solely consequential) by the decision, constituting the product system. The product system can be infinite, and propagated amount as well.

Absolutely: Decision and processes can be considered in past, present or future.

Relatively: Only considers processes after decision, i.e., no relative past consideration.

Can be both:

Separately: the additional processes induced by the decision.

Scenario: difference between the impact of different realistic scenarios that represent decision choices.

Not restricted.

The complete processes are considered with additional co-function effects. The latter are dependent on the market, an example of a co-function effect is substitution. An alternative is system expansion.

Consequential suppliers need to be considered Amount-specific effects is advised but in practice average or marginal impact effects are possible. Average or marginal product consideration is possible.

Environmental impact assessment is completely consequential and unbound, leading to a possibility for full integration with the product system.

From a theoretical perspective, if the desire is to also cover CLCA, at least two crucial changes are needed for the ISO text:

(1). Decouple the definition of product system and product life cycle, and have an LCA be a study of a product system with exclusion of mentioning of product life cycle. Only for ALCA, a product system would equal a product life cycle. For CLCA, a product system would be possibly different from a product life cycle, and that's why their definitions need to be independent and that of product system generalized. See also Section 2.2.1 on this matter.

(2). Concerning multifunctionality, the prioritization and limitation of solutions for multifunctionality should be dropped. The first option of subdivision can be kept, although it is in fact rather a prevention of the problem than a solution for it. It should be specified that the solution for multifunctionality is dependent on the goal, which negates this absolute prioritization for any LCA. If desired to further specify solutions, a distinction should best be made between attributional and consequential LCA. Moretti et al. [88], and indirectly Schrijvers et al. [57], also advise to distinguish between these and link multifunctionality solutions to them. Furthermore, it should be mentioned that system expansion is possible for both ALCA and CLCA, and that 
for CLCA, alternatives are possible, including avoided burden. See also Section 3.5 on this matter. (The recent 2020 amendment of ISO 14044 defines "System expansion avoids allocation by integrating a functionally equivalent product system, that is assumed to be substituted by the co-product (product B), within the system boundary". However, then system expansion would only be equal to avoided burden or substitution, losing the conceptual idea of expanding the functional unit and the system. There are moreover also other ways to address the effect of co-products in consequential LCA such as product benefit characterization [80].)

It is also striking to point out that there is a short mentioning of two different approaches which closely relate with the ALCA and CLCA concepts (Annex A of 14040), but they are not named as attributional or consequential, nor are they completely in line with the UNEP-SETAC [31] definitions to which we adhere here. Nevertheless, for the "possible (future) changes between alternative product systems" as mentioned in Annex A, the product system cannot be equal to a product life cycle. Mentioning this other approach in Annex A of the ISO implies thus an inconsistency and could be resolved by applying the first crucial change as highlighted above. Moreover, in the same annex is mentioned that "the products and processes studied in an LCA are those affected by the decision that the LCA intends to support", which relates with the scope of CLCA. This also points out an inconsistency in the ISO 14040 text between, on the one hand, a product system that is equal to a product life cycle, and, on the other hand, a product system of which processes should be the those affected by a decisions, which may not necessarily be the product life cycle. For example, the decision to buy a car does not affect its preceding production anymore.

When it comes to ALCA, it is in line with the ISO standards documentation, except for the above aspects of the annex A of ISO 14040 where a product system strictly relates with the effect of decisions and CLCA. In other words, to comply with ALCA, this statement should not be generalized or left out in ISO 14040. Besides that, the ISO standards as they are now, do not imply all theoretical rules that are part of ALCA. More precisely, there are no restrictions on additivity or on the partitioning of LCIA processes, which are both needed for ALCA. This means that ALCA complies with the ISO standards on these aspects, but that these ISO standards are also not limited to these, i.e., the ISO standards LCA notion does not coincide with ALCA.

\subsection{Can an Attributional Model Be Used for a Consequential Concept/Question, or Vice Versa?}

We have defined the ALCA and CLCA concepts and what their modelling restrictions imply as specified in Table 5. Developed models that follow these restrictions can be called attributional and consequential models/modelling frameworks that, respectively, were developed to answer the attributional and consequential type of research questions. At this point, it is already clear that these concepts differ considerably (Table 1), but here we will specifically focus on whether an attributional model can theoretically answer a consequential question, or vice versa, and to which extent. In other words, we address the question whether, theoretically, the modelling restrictions of ALCA comply with that of CLCA, vice versa? First of all, this would be of interest for models that relate with the same or very similar functional unit as that of the other research question type. For example, to which extent can an ALCA model developed to address what the impact is of the product life cycle of a car for a $1 \mathrm{~km}$ drive, be used to answer a CLCA question on the impact of an extra demand for $1 \mathrm{~km}$ driven with a car? We will go through each of the theoretical aspects of Table 5 : 
- $\quad$ Basic concept related with relation to global burden (Section 2.2): It is imperative to realize that the scope of the modelling is different. An attributional model will propagate the environmental impact of a product life cycle (e.g., that of a car), with it being a share of a global impact. A consequential model will propagate the environmental impact of a decision (e.g., the decision to demand an extra $\mathrm{km}$ driven with a car), i.e., the difference in global impact between two plausible worlds: a world with and without that decision (e.g., with and without that extra $\mathrm{km}$ driven). The studied systems will differ. An attributional model could be used for a consequential question if the share of the global burden of the ALCA model equals the change induced by a decision as done by the CLCA model. Yet, there is nothing that theoretically guarantees their equality, failing to ensure, from a theoretical perspective, the use of attributional models for a consequential question or vice versa. A comparison of two ALCA model outcomes could be considered, with and without the decision, but the rules (as defined in the ALCA definition; see also Appendix A.3) that specify the shares of the global burden are different from that which define the difference in global impacts between a world with and without the decision.

- Relationships and boundaries of product systems (Section 3.1): An attributional model would fail to cover other types of consequential flows and effects, besides physical and service ones, most notably: information flows. To the contrary, a consequential model would cover too much types of interactions to be for sure in line with the attributional concept.

- The aspect of time (Section 3.2): When considering a product at a certain point in time, an attributional model would also consider the relative past processes that have created that product, whereas this is irrelevant for a consequential LCA concerning a decision to buy that product. The other way around, a consequential model will not cover this relative past. However, an extra demand of a product may induce production of a similar product in the future, as elaborated by Schaubroeck et al. [36], and the past processes could be seen as an approximation for future ones. Yet, for other types of decisions, this is less the case, e.g., a decision to handle waste will less likely induce the new generation of waste. This time consideration remains a considerable difference between both models and may hamper approximation of a consequential question with an attributional model.

- Specify product system separately or in scenarios (Section 3.3): When considered independent from other aspects, whether an attributional model is presented in scenarios or just the product system will not make a difference in the extent to which it can answer a consequential question, or vice versa.

- Constraints in mathematical modelling (Section 3.4): Since there is no limitation for CLCA, an attributional model, which is strictly additive (e.g., linear), is not limited in this regard to answer a consequential question, but it will do so in a more flawed manner than an adequate non-linear model. However, a non-additive consequential model (e.g., certain non-linear ones) may not be used to answer an attributional question, as the ALCA concept restricts models through the additivity requirement.

- Concerning solutions for multifunctionality (Section 3.5): The necessary use of partitioning to address multifunctionality issues in an attributional model causes considerable incompliance with a consequential model. A partitioned or partially finalized process will never be plausible, e.g., as a consequence of a decision, directly or indirectly. For a finalized process, partial inventories cannot be considered realistic. For example, consider the cogeneration process (electricity \& heat), with $x \mathrm{~kg} \mathrm{CO}$ emitted per production of $1 \mathrm{MJ}$ heat and $0.5 \mathrm{MJ}$ of electricity. When demanding $1 \mathrm{MJ}$ heat, there will always be an emission of $x \mathrm{~kg} \mathrm{CO}_{2}$ (with a cogeneration of $0.5 \mathrm{MJ}$ of electricity), and not just of $x \times 1 / 1.5 \mathrm{MJ} \mathrm{CO}_{2}$, which is an artificial amount. The solutions of a consequential model, e.g., avoided burden, may violate the additivity requirement of ALCA, which makes it also ill advised to use a consequential model to answer an attributional question. 
- Marginal versus average considerations (Section 3.6): First of all, average and marginal does not relate to the suppliers of attributional and consequential LCA, respectively. The type of "suppliers" differs, as attributional models will cover interlinked actual suppliers, whereas consequential the ones affected (indirectly) by the decision. It might be that the affected suppliers are the actual interlinked ones, which might seem more plausible for low amounts, but this is not a guaranteed matter. Coming back on the marginal versus average matter, the only limitation for attributional models is that either average or marginal derivations for LCIA should be consistently considered, but this does not hinder its usage to answer a consequential question.

- Framing of the product system and impact assessment (Section 3.7): The LCIA of an attributional model, will also have partitioned processes, creating an issue in its use to answer a consequential question. However, on other matters (e.g., type of relationships or additivity-restricted), there is no issue to answer a consequential question, but there will be a lower adequacy to address all non-linear relationships.

This overview highlights the major difference in modelling in almost all these aspects, from a theoretical viewpoint, and emphasizes the need to, if achievable, best use attributional LCA models for an attributional LCA question, and a consequential LCA model for a consequential LCA question. Indirectly, this analysis also underscores the difference between the ALCA \& CLCA concepts and models further. Posing either an attributional or consequential type of research question, will have considerable impact on the modelling outcome and its further usage in society. Notably, Weidema [87] illustrates the extent of difference between the LCA modelling outcomes of a consequential and attributional version of a database. More precisely, for respective LCIA results is mentioned that $67 \%$ of the results show more than $10 \%$ difference, $22 \%$ more than $100 \%$ difference and for $5 \%$ of the results the differences are above an order of magnitude. However, in practice, there are always practical constraints (e.g., concerning data \& model quality and availability), which could allow flexibility in the modelling type under certain conditions. Moreover, as already discussed in Section 2.1, in practice, attributional modelling aspects are even combined with consequential ones, leading to combinatory modelling approaches. In those cases, theoretically, new concepts, which are a combination of ALCA and CLCA aspects, should be defined, but these combinatory approaches may also have been applied because of practical limitations. Yet, overall, a full analysis of these practical aspects, and whether it would seem acceptable to use attributional modelling for consequential LCA, or vice versa, is out of the scope of this study.

\section{Conclusion and Further Outlook}

\subsection{Relevance of This Work in Hindsight}

In this work we have consolidated and further specified the methods ALCA and CLCA. The implications of their discrepancies are not only clear from a theoretical viewpoint but these methods lead to very different outcomes, i.e., associated databases and case studies have exemplified that completely different results and conclusions can be obtained [80,87]. Yet, despite this, there is a lot of ambiguity and issues surrounding these methods in literature, as brought forward in this article. Three prominent ones are:

(1). There are misconceptions of what the concepts entail. For example, CLCA is still recently wrongly considered as a method that is theoretically typical for large-scale decisions [30,102] and/or only additionally considers market mechanisms, such as price changes $[25,34,103]$. These restrictions would be incorrect from a theoretical perspective, following the definition we argue here (see Table 1).

(2). The main key standard text on LCA, ISO 14040-14044, remains vague and contradictory regarding these methods. The main body of ISO 14040-14044 has a definition of product system that relates with product life cycle (ALCA) but then in annex A of ISO 14040, a definition linked with CLCA is given. Theoretically, it cannot be both. Furthermore, concepts are also brought forward in that annex A that are very close to 
ALCA and CLCA, but they are not called like that, adding more to the confusion (see Section 3.9).

(3). There seems to be also a tendency of ignoring ALCA and CLCA in literature, which could also be linked with a lack in clarity. Most notably, for the multifunctionality issue, ALCA and CLCA theoretically necessitate different types of solutions, and this has been overlooked or ignored in literature. This has been discussed by Schaubroeck et al. [80] (see also Section 3.5).

There is thus a dire need for more clarity and consensus on these methods and their characteristics, which this work addresses. It is the key added value of our article. As presented in another article in this journal [104], in the field of LCA, consolidation is necessary right now, to which our work contributes. Furthermore, for a quick overview of prominent and specific novelties in this work, please see the table in Appendix A.4.

Our analysis of definitions based on criteria, brings forward the definitions of ALCA and CLCA present in UNEP-SETAC [31] as the advised ones, mainly because they are the most conventional ones. The definitions are presented in Table 1 and the characteristics in Table 5. Despite the fact that these definitions are quite old, which also goes for the ISO 14040-14044 standards we considerably follow (except for on some crucial topics), the value and consensus of definitions is not defined by age. These ALCA and CLCA definitions and concepts have not been discarded and are still considerably applied, or at least intended to be. There are some newly derived concepts or even debates on them, but we have addressed literature on the latter. In fact, we consider our work to be a first completely thorough and scientific derivation of the implications of these definitions, paving the way for clear and directed scientific developments and communications. Modelling frameworks and applications have commonly evolved to obtain a (presumed) higher empirical accuracy or completeness, but without a clear alignment with a concept, their value remains questionable. In this sense, our article rather aids practitioners in understanding which modelling choices they can make (e.g., non-linear modelling for CLCA), considering restrictions, and what questions modelling frameworks serve.

Unlike modelling frameworks and applications, concepts do not have to evolve, e.g., for scientific accuracy, as their value depends on their affinity for answering relevant societal questions. Yet, in this article it is not the idea to judge or value the two approaches and their characteristics, but rather to present them in an objective and structured manner. We do not focus on the judgement of relevance (e.g., in case of decision support) or responsibility implications of ALCA or CLCA, as studied in various recent works $[37,56,74,105]$, which are after all not explicitly mentioned or discussed in the UNEPSETAC [31] definitions in hindsight. Furthermore, the notion of "responsibility" is a very value-laden notion that goes beyond the objective concepts and research questions of UNEP-SETAC [31], but arguably rather relates with actors/stakeholders (not just decisions or products), and among else the extent of an actor's influence, of which the latter pointed out by Weidema et al. [105]. The same goes for the concept of "accountability", similar to the notion of responsibility, which Schrijvers [56] associated with ALCA because among else in UNEP-SETAC [31] is mentioned "accounting" approach for ALCA. Yet, accounting refers to a descriptive approach, underscored by also the mentioning of "descriptive approach" for ALCA in the UNEP-SETAC report [31], relating to the notion of keeping records or summarizing, analyzing something, and thus not a value-laden judgement. Nevertheless, such an evaluation of relevance of ALCA and CLCA could be made, but is not brought forward in the UNEP-SETAC [31] definitions of ALCA and CLCA. Hence, it is also not part of our objective analysis in which we only cover matters that are explicitly mentioned in the definitions or can unequivocally be derived from them. We foresee further research that covers these aspects of relevance (including data availability and modelling efforts), extent of decision-support and responsibility implications, but saw it as essential to first have outlined the specific objective aspects of the ALCA and CLCA approaches in this elaborate separate article. 


\subsection{Reflections on Fixing of Definitions}

Coming back on fixing of definitions, there are certain elements of the definitions, and thus the associated concepts, that some scientists may not agree with or find incomplete, but that incompleteness is the inherent issue with any definition. For example, for the CLCA definition, one could argue that a "decision" may not necessarily lead to an "action", as one may change their minds, i.e., come back on a decision. Theoretically, a possibility of a change in mind should be considered and as well the time span between decision and action. In practice, this may be neglected based on a presumption, but it is a modelling rule, not theoretically argued. Palazzo et al. [5] already use more the word "action" in their review on modelling frameworks for CLCA, but do not go deeper into this from a conceptual perspective.

A definition of a word can be associated with but is not a scientific concept or model that should be freely altered by a single individual and the fixation of a definition somewhat goes beyond the field of science into that of consensus and agreement at a community level. To the contrary, a scientific argument is ideally not correct because of agreement or convention but because of logic and empirical evidence. The only issue would be if the definition is illogic, which necessitates an alteration. See also Section 2.1 on this matter.

Overall, we advise any new definition or alteration in the definition, uses another name (e.g., "attributional2" definition) or is followed by an agreement at scientific community level, e.g., supported by UNEP or through ISO. As a plausible example of new definitions, one could consider the "consequential_action" LCA definition as one in which decision is replaced by action in the UNEP-SETAC [31] one, and the "attributional_new" LCA definition, as one with "physical" replaced by "mass" or "material". Yet, these matters are not pertaining to illogical aspects, nor may they necessitate a hastily community gettogether for a reconsideration, in our opinion. The only exception would be that products should be covered and not just "a product" in the aim of ALCA, but this is regarded as a small unintended mistake, since multiple products is implied in the rest of the UNEPSETAC [31] document (See Section 2.2.1). We still advise to follow the UNEP-SETAC [31] definitions, and this article may though help in improving further possible agreed upon alterations as we here outline all objective implications of the original ones. Nevertheless, as already mentioned, if we do not stick to definitions that have been agreed upon by a community or at least a substantial part of it, we may hinder communication and thus (scientific) advancement considerably, as similarly raised for another scientific concept [106]. Lastly, on this matter, there are some discrepancies between UNEP-SETAC [31] definitions and ISO 14040-14044 guidelines (see Section 2.2.1), which are both documents at a larger community level, although the communities are different in each case. This necessitates a consolidation. Here, we though stick with the UNEP-SETAC [31] definitions as they explicitly bring forward and distinguish the concepts of ALCA and CLCA. The proposed changes for ISO-compliance in Section 3.9 could support such a consolidation.

\subsection{Overall Discrepancy between ALCA and CLCA}

The overall discrepancy between ALCA and CLCA is related with the extent of the rules. In CLCA, there is only one rule, namely the consideration of consequential effects, and a broad range of modelling frameworks are possible. For ALCA, there are more rules that imply restrictions (processes are interlinked through physical/energy and service flows, additivity-restricted modelling, additivity check and partitioning). These already delimit the modelling framework considerably. Yet, there is also the explicit consideration of consequential effects for LCIA and some implicit considerations of consequential effects possible for the product system (see Appendix A.3 in the Appendix A for an overview). This combination of consequential and normative (rule-based) perspectives does not imply an insurmountable issue, since concepts can be the combination of different thinking (which is also the case in society, where we based judgement on both consequential and normative ethics). Yet, the nature of the final resulting environmental impact of ALCA, would then be a combination of normative and consequential thinking. The resulting estimated 
environmental impact amount through ALCA cannot be seen as a pure consequence of the product or product life cycle, nor as a pure normative evaluation.

\subsection{Other Sustainability Pillars and Aspects}

Lastly, despite the focus of this work on the environmental pillar of sustainability (LCA), attributional and consequential considerations brought forward in this work can also be applied for economic (life cycle costing), social impact (social life cycle assessment) and sustainability impact as a whole (life cycle sustainability assessment) [50,107,108] The main thing that should be altered is to consider, besides environmental effects, also economic and social relations and effects. Besides that, all the other considerations of this work should still hold. For example, for life cycle costing approaches [109], attributional LCC would among else imply consideration of financial cash flows of the interlinked processes, e.g., cost of the actual production of the product prior to its delivery and revenue afterwards. To the contrary, consequential LCC would among else cover the induced cash flows by the decision, e.g., product purchase will lead to revenue injected in the market, where it can then be spend on new ingredient purchases or investments etc. Further research is needed to illustrate this elaborately. In this work we focus on assessment, but more concrete managerial methods can aid in achieving sustainability in general [110].

Finally, a truly consequential approach should also cover the characterization of product benefit, even of the product of interest, otherwise the comparison with the reference scenario is not complete towards coverage of all consequential effects, e.g., coproduct amounts may, instead of just lowering its alternative production (see substitution approach in Section 3.5), also be more consumed inducing product benefit $[50,84]$.

Author Contributions: Conceptualization, T.S.; writing-original draft preparation, T.S., S.S., R.H., M.B., A.Z. and E.B.; writing-review and editing, T.S., S.S., R.H., M.B., A.Z. and E.B.; visualization, T.S.; supervision, E.B. All authors have read and agreed to the published version of the manuscript.

Funding: This research received no external funding.

Data Availability Statement: Not applicable.

Acknowledgments: We would like to thank Yi Yang, Dieuwertje Schrijvers, Elorri Igos, Paul Baustert, Massimo Pizzol, Roger Burritt \& Matthew Brander for reflections that helped to improve the article. We are especially grateful towards Bo Weidema \& Tomas Ekvall for their considerable input and feedback. These acknowledged individuals do not necessarily endorse this work.

Conflicts of Interest: The authors declare no conflict of interest. The funders had no role in the design of the study; in the collection, analyses, or interpretation of data; in the writing of the article, or in the decision to publish the results.

\section{Appendix A}

Appendix A.1. Overview of Definitions of Key Terms as Used in This Article

Table A1. Overview of the definitions of key terms as used in this article.

\begin{tabular}{|c|c|c|c|c|}
\hline Term & $\begin{array}{l}\text { Definition in Dictionary } \\
\text { (Cambridge Online } \\
\text { Dictionary 29.01.21) }\end{array}$ & $\begin{array}{l}\text { Specification in This Context, based } \\
\text { on the Definition in the Dictionary }\end{array}$ & Example of Figure 1 & $\begin{array}{l}\text { Example in the Context of } \\
\text { ALCA \& CLCA }\end{array}$ \\
\hline Method/approach & $\begin{array}{c}\text { Method: " a particular way of } \\
\text { doing something" } \\
\text { Approach: " a way of } \\
\text { considering or } \\
\text { doing something" }\end{array}$ & $\begin{array}{l}\text { In this context, we focus on a } \\
\text { scientific method that addresses how } \\
\text { something will be done in a } \\
\text { scientific way. }\end{array}$ & The Water flow method & e.g., LCA, ALCA, CLCA \\
\hline
\end{tabular}


Table A1. Cont.

\begin{tabular}{|c|c|c|c|c|}
\hline Term & $\begin{array}{l}\text { Definition in Dictionary } \\
\text { (Cambridge Online } \\
\text { Dictionary 29.01.21) }\end{array}$ & $\begin{array}{l}\text { Specification in This Context, based } \\
\text { on the Definition in the Dictionary }\end{array}$ & Example of Figure 1 & $\begin{array}{l}\text { Example in the Context of } \\
\text { ALCA \& CLCA }\end{array}$ \\
\hline Concept & $\begin{array}{c}\text { Concept: "a principle } \\
\text { or idea" } \\
\text { "an idea, theory, etc. about a } \\
\text { particular subject" }\end{array}$ & $\begin{array}{l}\text { The concept of a method, the point } \\
\text { of focus here, implies the theoretical } \\
\text { dimension of it. It will specify what } \\
\text { that "something" is. It may thus } \\
\text { relate with a certain (type of) goal or } \\
\text { research question type. }\end{array}$ & $\begin{array}{l}\text { Approach to address the } \\
\text { amount of water flowing in } \\
\text { a river. }\end{array}$ & $\begin{array}{l}\text { e.g., for CLCA: "The } \\
\text { consequential approach } \\
\text { attempts to provide information } \\
\text { on the environmental burdens } \\
\text { that occur, directly or indirectly, } \\
\text { as a consequence of a decision } \\
\text { (usually represented by changes } \\
\text { in demand for } \\
\text { a product)." }\end{array}$ \\
\hline $\begin{array}{l}\text { (Conceptual) } \\
\text { characteristics }\end{array}$ & $\begin{array}{l}\text { Characteristic: "a typical or } \\
\text { noticeable quality } \\
\text { of someone } \\
\text { or something." "a typical or } \\
\text { noticeable feature of someone } \\
\text { or something" }\end{array}$ & $\begin{array}{l}\text { A certain conceptual characteristic of } \\
\text { a method, will entail a certain } \\
\text { quality or feature of it. }\end{array}$ & $\begin{array}{l}\text { A conceptual characteristic } \\
\text { is that it deals with } \\
\text { flowing water }\end{array}$ & $\begin{array}{l}\text { e.g., a characteristic of ALCA is } \\
\text { that of additivity, as described } \\
\text { in Table 1: "In theory, if one } \\
\text { were to conduct attributional } \\
\text { LCAs of all final products, one } \\
\text { would end up with the total } \\
\text { observed environmental } \\
\text { burdens worldwide" }\end{array}$ \\
\hline Modelling framework & $\begin{array}{l}\text { In the context of mathematics } \\
\text { and computing, modelling: " } \\
\text { the activity of using } \\
\text { mathematical models } \\
\text { (=simple descriptions of a } \\
\text { system or process) to make } \\
\text { calculations or predict what } \\
\text { might happen" } \\
\text { Framework: "a system of } \\
\text { rules, ideas, or beliefs that is } \\
\text { used to plan or } \\
\text { decide something" }\end{array}$ & $\begin{array}{l}\text { The modelling framework of a } \\
\text { method, the point of focus here, } \\
\text { covers the practical manifestation of } \\
\text { it. It will entail an operational model } \\
\text { based on a set of rules, such as } \\
\text { mathematical models. } \\
\text { Comment: Because of practical } \\
\text { limitations, it can be that a modelling } \\
\text { framework does not entirely live up } \\
\text { to the theoretical or conceptual } \\
\text { requirement of the method. (in fact, } \\
\text { it hardly is the case). Moreover, a } \\
\text { modelling framework developed for } \\
\text { method A, could be considered for } \\
\text { method B, but then there might be } \\
\text { conflict in certain conceptual aspects } \\
\text { not being fulfilled. }\end{array}$ & $\begin{array}{l}\text { A certain model, i.e., set of } \\
\text { equations, that allows to } \\
\text { calculate the amount of } \\
\text { water flowing in a river } \\
\text { based on certain input data }\end{array}$ & $\begin{array}{l}\text { The modelling framework for } \\
\text { CLCA as presented by } \\
\text { Weidema et al. (2013) and } \\
\text { operational in Simapro. }\end{array}$ \\
\hline Application & $\begin{array}{c}\text { Application: "the act of using } \\
\text { something for a } \\
\text { particular purpose" }\end{array}$ & $\begin{array}{l}\text { In our context, it implies the use of a } \\
\text { modelling framework with a certain } \\
\text { specific input (e.g., certain input } \\
\text { values), providing a specific output } \\
\text { (e.g., certain output values). }\end{array}$ & $\begin{array}{l}\text { An application for a } \\
\text { specific river (e.g., Danube } \\
\text { river) with input data (e.g., } \\
\text { water height) }\end{array}$ & $\begin{array}{l}\text { e.g., the application of CLCA to } \\
\text { a case on car replacement, as } \\
\text { done in the work of } \\
\text { Schaubroeck et al. [36] }\end{array}$ \\
\hline Modelling restrictions & $\begin{array}{l}\text { Restriction: " something that } \\
\text { limits someone's actions or } \\
\text { movement, or limits the } \\
\text { amount, size, etc., } \\
\text { of something" }\end{array}$ & $\begin{array}{l}\text { A restriction imposed on the model } \\
\text { (e.g., it can be only additive). In our } \\
\text { context, it relates to the restrictions } \\
\text { set out by the concept and its } \\
\text { characteristics. If a modelling } \\
\text { framework does not meet these } \\
\text { restrictions, in theory, it does not } \\
\text { answer the associated type of } \\
\text { research question. }\end{array}$ & $\begin{array}{l}\text { A modelling restriction } \\
\text { example is the focus on } \\
\text { using physics equations } \\
\text { that apply to fluids }\end{array}$ & $\begin{array}{l}\text { e.g., a modelling restriction } \\
\text { imposed by the additivity } \\
\text { requirement of ALCA, is that a } \\
\text { modelling framework should } \\
\text { follow that rule (e.g., } \\
\text { guaranteed by linearity) }\end{array}$ \\
\hline
\end{tabular}

\section{Appendix A.2. Mathematical Elaboration}

This part of the appendix provides a mathematical elaboration of the mathematical model types (due to modelling restrictions) of ALCA and CLCA, without thus assuming a particular unique mathematical model. It is therefore quite abstract. Nevertheless, by the precision such a mathematical analysis requires, a few points of the main article can be articulated more clearly, and a few extra insights follow. The text builds further on the work of Heijungs and Guinée [111], but has also been improved.

\section{Appendix A.2.1. The General Function That Couples Products to Impacts}

The left panel of Figure 4 [21] presents the impact of the total societal system at some point over time (which may span past, present and/or future) as a pie. Let us indicate this total impact as I. I may be a vector, for instance containing elements for global warming, toxicity, acidification or human health, ecosystem quality, etc. For simplicity, and without loss of generality, we will here assume it is a scalar, for instance, the global warming indicator, in $\mathrm{kg}-\mathrm{CO}_{2}$-equivalents. 
The impact $I$ is modelled as a function of the products of concern (related to a decision in CLCA). Let us suppose that the bundle of products managed by society is specified by a vector $\mathbf{f}=\left(\begin{array}{c}f_{1} \\ f_{2} \\ \cdots\end{array}\right)$, where $f_{1}$ is the number of products of type 1 , etc. The function that models the impact is represented with the symbol $\gamma$. Therefore, we assume there is a function $\gamma$, such that:

$$
I=\gamma(\mathbf{f})
$$

We do not make any assumption here about the nature of $\gamma$. It may be linear or non-linear, regionalized or global, subdivided into LCI and LCIA or not, etc. The function $\gamma$ is probably informed by domain knowledge on chemical or mechanical engineering (emission factors, etc.) and ecology or environmental science (dose-response relationships, etc.). We just assume it is there, specified in mathematical form.

\section{Appendix A.2.2. Derivation of ALCA Model type, Focusing on a Linear Model}

In ALCA modelling, we now wish to find the part of the impact cake $(I)$ that is associated with a certain amount of a specific product. Let us suppose this is product $i$, of which we study an amount $\phi$. A concrete example would be $1000 \mathrm{~L}$ of beer. Typically (but not necessarily), $f_{i}$ is a much larger amount, say 100 million liters of beer, and is the amount of product used by society over the considered scope. The amount of impact attributed to $\phi$ units of product $i$ will be indicated by $I_{A L C A, i}(\phi)$. But how this amount is to be calculated depends on normative principles. Considering the conceptual restriction of additivity achieved through linearity per product type, a straightforward formulation is:

$$
I_{A L C A, i}(\phi)=C_{i} \frac{\phi}{f_{i}} I
$$

where $C_{i}$ is a constant. These constants are fixed by the rule that the sum of impacts of all products equals to the total impact:

$$
\sum_{i} I_{A L C A, i}\left(f_{i}\right)=\sum_{i} C_{i} \frac{f_{i}}{f_{i}} I=I
$$

so that:

$$
\sum_{i} C_{i}=1
$$

Further guidance on choosing $C_{i}$ for ALCA will be discussed later on. Note that we can rewrite the expression for $I_{A L C A, i}(\phi)$ as:

$$
I_{A L C A, i}(\phi)=D_{i} \phi
$$

where $D_{i}$ is a constant that depends on the product type $\left(D_{I}=\frac{C_{i} I}{f_{i}}\right)$. This form emphasizes the linearity for amounts per product type of the ALCA model type. That was demanded a priori, but is a useful check that the final result indeed works like this.

Observe that the mathematical form of $\gamma$ does not enter the formulas for ALCA modelling. We use the amount of impact $I$, and we use normatively defined constants $C_{i}$, but not $\gamma$ itself.

Appendix A.2.3. Derivation of CLCA Model Type, with Optional Linearity

In CLCA modelling, we work with changes, starting with a change in demand. When only focusing on a change in product demand, suppose that the demand for product $i$ is 
changed from $f_{i}$ into $f_{i}+\delta$. As a result, the impact of society will change from $I$ into $I^{\prime}$, given by:

$$
I^{\prime}=\gamma\left(\begin{array}{c}
f_{1} \\
\cdots \\
f_{i}+\delta \\
\cdots
\end{array}\right)
$$

The difference between $I^{\prime}$ and $I$ is the impact that will be associated with the extra product $i$ :

$$
I_{C L C A, i}(\delta)=I^{\prime}-I=\gamma\left(\begin{array}{c}
f_{1} \\
\cdots \\
f_{i}+\delta \\
\cdots
\end{array}\right)-\gamma\left(\begin{array}{c}
f_{1} \\
\cdots \\
f_{i} \\
\cdots
\end{array}\right)
$$

This elaboration follows a scenario comparison approach (Section 3.3). Because we have not specified the precise form of $\gamma$, this expression cannot be further worked out. However, if $\delta$ is small compared to $f_{i}$, we can approximate $I_{i}^{\prime}$ using the partial derivative $\frac{\partial \gamma}{\partial f_{i}}$, evaluated locally at the point $\mathbf{f}$ (which may be in past, present or future, or any hypothetical scenario):

$$
I^{\prime} \approx I+\left.\left(\frac{\partial \gamma}{\partial f_{i}}\right)\right|_{\mathbf{f}}
$$

which implies that:

$$
\left.I_{C L C A, i}(\delta) \approx\left(\frac{\partial \gamma}{\partial f_{i}}\right)\right|_{\mathbf{f}} \delta
$$

When the impact function $\gamma$ has been specified, this local partial derivative is just a number which only depends on the product type $i$. Therefore, we write:

$$
E_{i}=\left.\left(\frac{\partial \gamma}{\partial f_{i}}\right)\right|_{\mathbf{f}}
$$

and hence:

$$
I_{C L C A, i}(\delta) \approx E_{i} \delta
$$

So, within this limit of small changes, CLCA modelling can be approximated by a linear function. Yet, it is best approached by a non-linear function. The latter formulation also represents a computation in a reference environment (see Section 3.3).

Observe that the mathematical form of $\gamma$, or more precisely, its local derivative $\left(\frac{\partial \gamma}{\partial f_{i}}\right)$, is needed to find the constants $E_{i}$, but that no normative rules are included.

\section{Appendix A.2.4. Contrasting ALCA and CLCA}

Summarizing the result so far:

ALCA linear modelling attributes a share of the total impact $I$ to $\phi$ units of product $i$ according to $I_{A L C A, i}(\phi)=D_{i} \phi$, where $D_{i}$ is defined by normative rules.

CLCA modelling, in case of covering the effect of a change in demand of $\delta$ units of product $i$, boils down to $I_{C L C A, i}=\gamma(\mathbf{f}+\boldsymbol{\delta})-\gamma(\mathbf{f})$. The function $\gamma$ is typically non-linear and openly defined. A mathematical simplification is possible using a partial derivative, leading to following linear function $I_{C L C A, i}(\delta) \approx E_{i} \delta$, where $E_{i}$ is defined by the local partial derivative of the impact function $\left(E_{i}=\left.\left(\frac{\partial \gamma}{\partial f_{i}}\right)\right|_{\mathrm{f}}\right)$. This seems only acceptable for small amounts $\delta$ and should not be regarded as general. Consequential modelling is not restricted to be linear. 
Appendix A.2.5. In Terms of Conventional Matrix-Based LCA Calculations

In conventional common practice process-based LCA and in IO-based LCA, the impact $I$ is often expressed using the following linear function of the amounts of products, in which $I$ is linear per $f_{i}$ (with all process data fixed, the impact varies linearly with $f_{i}$ ):

$$
I=\gamma(\mathbf{f})=\sum_{i} \alpha_{i} f_{i}
$$

where the constants $\alpha_{1}, \alpha_{2}, \cdots$ are based on unit processes, IO-tables, characterisation factors, etc. Part of this conventional nature is based on the fact that databases and software for LCA are constructed in that way, regardless the question if the LCA is an ALCA or a CLCA. For instance, if we use the classical matrix expression, with A the matrix for process amounts, B the matrix for elementary flows and $\mathrm{q}$ the vector with characterization factors (impact per elementary flow), then we can write the equation as:

$$
I=\mathbf{q}^{\mathrm{T}} \mathbf{B} \mathbf{A}^{-1} \mathbf{f}
$$

it readily follows that:

$$
\alpha_{i}=\left(\mathbf{q}^{\mathrm{T}} \mathbf{B} \mathbf{A}^{-1}\right)_{i}=\sum_{k} \sum_{j} q_{k} b_{k j}\left(\mathbf{A}^{-1}\right)_{j i}
$$

The local derivative $\left.\left(\frac{\partial \gamma}{\partial f_{i}}\right)\right|_{\mathbf{f}}$ is then simply:

$$
\left.\left(\frac{\partial \gamma}{\partial f_{i}}\right)\right|_{\mathbf{f}}=\alpha_{i}
$$

so that CLCA-style of computations could rely on a number of matrix operations, without actually doing a differentiation, when considering a linear simplification. This is not the general rule in CLCA, but it in any case applies to CLCA studies that rely on conventional LCA software, and thus limited linear modelling. In that case, even the approximate character and the restriction to small changes can be released, because in such a model the derivative is constant throughout. As a result:

$$
I_{\text {conventional-CLCA,i }}(\delta)=\alpha_{i} \delta
$$

Moreover, the linear and additive nature, with regard to product amounts, of the classical model implies that there is a very easy way to solve the normative problem of ALCA. In fact, when we calculate the impacts of a world with only $\phi$ units of product $i$, we find:

$$
I_{\text {conventional-ALCA,i }}(\phi)=\alpha_{i} \phi
$$

In other words, both ALCA and CLCA modelling can be expressed through conventional limited linear LCA calculations, which may give the impression that there is no difference. However, these concepts are entirely different, meaning that mathematical modelling similarity (achieved through a choice for linear model in CLCA and for proportional modelling in ALCA) should not be used as a presumption for conceptual similarity.

\section{Appendix A.3. Rules in CLCA and ALCA}

The main rule that characterizes CLCA is that the consequential effects of a decision are considered, which both encompasses the consequential propagation in product system and environmental impact assessment (see Table A2 for an overview). The rules that characterize the framing of a product system in ALCA are here shortly summarized and are based on the UNEP-SETAC [31] report (Table 1). Processes are included if they are interlinked to the process that provides the functional unit; all these processes form the product life cycle. This inclusion is determined by tracking three flows: physical, energy or 
service. In other words, processes are thus considered and linked according to these flows. Furthermore, the resulting environmental impact from the product system must represent a share of the global burden. Moreover, the aggregate of all these shares will make up the total global burden. These rules have a significant impact on the ALCA product system. For example, for the additivity aspect, it means that it must be possible to differentiate shares of different products and add them up. This affects the links of all processes and resources that can be connected to different products according to the physical, energy flow or services. This issue almost always occurs as it is rare to find a product of which each process or resource is only uniquely sourced to that specific product. This issue of multifunctionality can be dealt with through partitioning or system expansion. Both are further explained in Section 3.5. This can also be an issue for LCIA of ALCA, in which processes with multiple inputs from industry should also be partitioned. Finally, because of this additivity, modelling is restricted, possibly only linear. For an overview of the rules on framing product systems in ALCA and CLCA, see Table A2.

Table A2. Overview of the concept and rules that constitute the different attributional and consequential LCA approaches. This table builds further on Table 1, in the sense that it specifies specific rules that are behind the concept. CLCA has no additional rules, whereas there are various for ALCA.

\section{CLCA}

The direct and indirect environmental

Basic concept/rule burdens of consequences of a decision are assessed-This follows pure consequential thinking. (there are no additional rules. What the

Additional conceptual restrictions/rules product system and impact entail, are based on consequential relationships and follow the basic concept to the letter)
ALCA

Defines a portion of the global burden that can be linked with a product life cycle, which is also the product system. What a "portion" and "product life cycle" entail, needs to be explained via additional rules

The specification of what a product life cycle encompasses: As presented in Table 1, the product life cycle is defined through the product system as the processes that interlink through physical, energy and service flows with the main process that provides the functional unit (rule $1 \&$ rule 2 ).

The "portion" is defined through: Theoretical additivity: the sum of all ALCA of all final products should represent total global burden (see Table 1). Moreover, this rule indirectly implies following modelling restrictions (see Section 3.4):

(a) Restricted modelling for both LCI and LCIA (e.g., guaranteed through linear ones)

(b) the need for a validity check to prevent double-counting for LCI; considered separate product amounts should not be higher than the global demand for that period

(c) to obtain the impact always for a single product, partitioning of the product system should occur

(d) for the environmental impact processes, a partitioning should be done if there are multiple inputs originating from the human/ industrial system 


\section{Appendix A.4. Overview of Specific and Prominent Novelties of This Work in the Context of ALCA and CLCA}

Table A3. Overview of specific and prominent novelties of this work in the context of ALCA and CLCA. For more information please see the reported section. Here, we have only listed the prominent novelties.

\begin{tabular}{cll}
\hline No. & \multicolumn{1}{c}{ Section } & \multicolumn{1}{c}{ Novelty } \\
\hline & & $\begin{array}{l}\text { The distinction between concepts, modelling frameworks and applications of methods } \\
\text { allowing to better define and grasp ALCA and CLCA. In literature these things have been } \\
\text { mistaken for one another in the context of ALCA and CLCA. For example, there is the } \\
\text { wrong notion that the CLCA concept only covers additional market mechanisms since a } \\
\text { lot of applications or modelling frameworks focus on these. }\end{array}$
\end{tabular}

$2 \quad$ Section 2.1

An elaborate evaluation of definitions using criteria, striving for objectivity, going beyond a mere biased selection of definitions. In literature, a thoroughly argued selection based on various criteria is lacking to the best of our knowledge.

\begin{tabular}{|c|c|c|}
\hline 3 & Section 2.2.1 & $\begin{array}{l}\text { Pointing out that the definition of product system according to CLCA and that of ALCA } \\
\text { as product life cycle, are not the same, and that the ISO } 14040 \text { is contradictory in } \\
\text { presenting in its main body the ALCA definition of product system but a definition } \\
\text { aligned with CLCA in its annex A. }\end{array}$ \\
\hline 4 & Section 3.1 & $\begin{array}{l}\text { Whereas it is clear that CLCA covers consequential effects, we have now also specified } \\
\text { that in ALCA this is not exclusively as preceding causes are also covered in the product } \\
\text { system. This negates recent thinking in literature that ALCA would be consequential [17]. }\end{array}$ \\
\hline 5 & Section 3.1.2 & $\begin{array}{l}\text { While in literature [ } 42] \text { it has been considered that impacts would be finite, we have } \\
\text { innovatively argued that these can be infinite. Hence, we have also pointed out that it } \\
\text { might be needed to have a certain cut-off. }\end{array}$ \\
\hline 6 & Section 3.2 & $\begin{array}{l}\text { In literature [23], it has already been made apparent that ALCA and CLCA can cover } \\
\text { processes and products in the past, present and future. Yet, in our work, we additionally } \\
\text { point out that for CLCA this is the relative future after the decision, whereas for ALCA } \\
\text { this covers past and future processes relative to the product delivery. }\end{array}$ \\
\hline 7 & Section 3.3 & $\begin{array}{l}\text { For a single LCA, we have brought forward that this can be considered both for ALCA } \\
\text { and CLCA by (a) the product system and its impact separately, and (b) a difference } \\
\text { between scenarios: one with and one without the product system. In case of CLCA these } \\
\text { scenarios are both realistic, while for ALCA the one without the product system is } \\
\text { artificial. Literature [7] had mainly only focused on scenarios for CLCA. }\end{array}$ \\
\hline 8 & Section 3.4 & $\begin{array}{l}\text { While in literature, CLCA has been brought forward as being restricted to linear } \\
\text { modelling [78], we have now clearly specified that it is not the case. We have also pointed } \\
\text { out that additivity may be reached by linearity in ALCA, but that other solutions to meet } \\
\text { the additivity requirement might exist. Furthermore, we have highlighted the need for a } \\
\text { double counting check in ALCA. }\end{array}$ \\
\hline 9 & Section 3.5 & $\begin{array}{l}\text { We have brought forward the overlooked issue of multi-input environmental processes } \\
\text { that should also be partitioned in case of ALCA. }\end{array}$ \\
\hline 10 & Section 3.6 & $\begin{array}{l}\text { In literature [43], average is commonly associated with ALCA and marginal with CLCA. } \\
\text { We have unraveled that this is not the case and that average and marginal should be } \\
\text { considered dependent on the case for ALCA and CLCA. }\end{array}$ \\
\hline 11 & Section 3.6 & $\begin{array}{l}\text { For LCIA, we have pointed out that amount-specific characterization is the ideal solution, } \\
\text { and that average and marginal considerations are just approximations. }\end{array}$ \\
\hline 12 & Section 3.7 & $\begin{array}{l}\text { Whereas in literature a distinction between attributional and consequential LCIA is } \\
\text { commonly not made, we have brought forward that additional restrictions for } \\
\text { attributional LCIA are needed due to additivity restrictions (e.g., partitioning of } \\
\text { multi-input environmental processes). }\end{array}$ \\
\hline
\end{tabular}

\section{References}

1. EU Commission Better Regulation Toolbox. Available online: https:/ / ec.europa.eu/info/law/law-making-process/planningand-proposing-law/better-regulation-why-and-how/better-regulation-guidelines-and-toolbox/better-regulation-toolbox_en (accessed on 5 February 2020).

2. Hellweg, S.; Canals, L.M.I. Emerging Approaches, Challenges and Opportunities in Life Cycle Assessment. Science 2014, 344, 1109-1113. [CrossRef] 
3. Guinée, J.B.; Cucurachi, S.; Henriksson, P.J.G.; Heijungs, R. Digesting the Alphabet Soup of LCA. Int. J. Life Cycle Assess. 2018, 23, 1507-1511. [CrossRef] [PubMed]

4. Porcelli, R.; Marazza, D.; Contin, A.; Righi, S. Subjectivity in the consequential approach to LCA: A review about the interpretation of the concept in literature. In Proceedings of the XIII Convegno della Rete Italiana LCA, Rome, Italy, 13-14 June 2019; pp. 447-452.

5. Palazzo, J.; Geyer, R.; Suh, S. A Review of Methods for Characterizing the Environmental Consequences of Actions in Life Cycle Assessment. J. Ind. Ecol. 2020, 24, 815-829. [CrossRef]

6. Soimakallio, S.; Cowie, A.; Brandão, M.; Finnveden, G.; Ekvall, T.; Erlandsson, M.; Koponen, K.; Karlsson, P.-E. Attributional Life Cycle Assessment: Is a Land-Use Baseline Necessary? Int. J. Life Cycle Assess. 2015, 20, 1364-1375. [CrossRef]

7. Zamagni, A.; Guinée, J.; Heijungs, R.; Masoni, P.; Raggi, A. Lights and Shadows in Consequential LCA. Int. J. Life Cycle Assess. 2012, 17, 904-918. [CrossRef]

8. Environmental Management_Life Cycle Assessment_Principles and Framework; ISO 14040; ISO: Geneva, Switzerland, 2006.

9. Environmental Management_Life Cycle Assessment_Requirements and Guidelines; ISO 14044; ISO: Geneva, Switzerland, 2006.

10. de Haes, H.A.U.; Jolliet, O.; Finnveden, G.; Hauschild, M.; Krewitt, W.; Müller-Wenk, R. Best Available Practice Regarding Impact Categories and Category Indicators in Life Cycle Impact Assessment. Int. J. Life Cycle Assess. 1999, 4, 66-74. [CrossRef]

11. Schaubroeck, T. Towards a General Sustainability Assessment of Human/Industrial and Nature-Based Solutions. Sustain. Sci. 2018, 13, 1185-1191. [CrossRef]

12. Weidema, B.P.; Schmidt, J.; Fantke, P.; Pauliuk, S. On the Boundary between Economy and Environment in Life Cycle Assessment. Int. J. Life Cycle Assess. 2018, 23, 1839-1846. [CrossRef]

13. Guinée, J.B.; Heijungs, R.; Huppes, G.; Zamagni, A.; Masoni, P.; Buonamici, R.; Ekvall, T.; Rydberg, T. Life Cycle Assessment: Past, Present, and Future. Environ. Sci. Technol. 2011, 45, 90-96. [CrossRef]

14. Heijungs, R. Economic Drama and the Environmental Stage: Formal Derivation of Algorithmic Tools for Environmental Analysis and Decision-Support from a Unified Epistemological Principle; Leiden University: Leiden, The Netherlands, 1997.

15. Schaubroeck, T.; Alvarenga, R.A.F.; Verheyen, K.; Muys, B.; Dewulf, J. Quantifying the Environmental Impact of an Integrated Human/Industrial-Natural System Using Life Cycle Assessment; A Case Study on a Forest and Wood Processing Chain. Environ. Sci. Technol. 2013, 47, 13578-13586. [CrossRef] [PubMed]

16. Baitz, M.; Albrecht, S.; Brauner, E.; Broadbent, C.; Castellan, G.; Conrath, P.; Fava, J.; Finkbeiner, M.; Fischer, M.; Fullana Palmer, P.I.; et al. LCA's Theory and Practice: Like Ebony and Ivory Living in Perfect Harmony? Int. J. Life Cycle Assess. 2013, 18, 5-13. [CrossRef]

17. Yang, Y. A Unified Framework of Life Cycle Assessment. Int. J. Life Cycle Assess. 2019, 24, 620-626. [CrossRef]

18. Suh, S.; Yang, Y. On the Uncanny Capabilities of Consequential LCA. Int. J. Life Cycle Assess. 2014, 19, 1179-1184. [CrossRef]

19. Ekvall, T. Moral Philosophy, Economics, and Life Cycle Inventory Analysis; SAE International: Warrendale, PA, USA, 2000.

20. Tillman, A.-M. Significance of Decision-Making for LCA Methodology. Environ. Impact Assess. Rev. 2000, 20, 113-123. [CrossRef]

21. Weidema, B.P. Market Information in Life Cycle Assessment; Enviromental Project No. 863; Danish Enviromental Protection Agency: Copenhagen, Denmark, 2003.

22. Weidema, B.P. Market Aspects in Product Life Cycle Inventory Methodology. J. Clean. Prod. 1993, 1, 161-166. [CrossRef]

23. Brandão, M.; Martin, M.; Cowie, A.; Hamelin, L.; Zamagni, A. Consequential life cycle assessment: What, how, and why? In Encyclopedia of Sustainable Technologies; Elsevier: Amsterdam, The Netherlands, 2017; pp. 277-284. ISBN 978-0-12-804792-7.

24. Brander, M. Conceptualising Attributional LCA Is Necessary for Resolving Methodological Issues Such as the Appropriate Form of Land Use Baseline. Int. J. Life Cycle Assess. 2016, 21, 1816-1821. [CrossRef]

25. Earles, J.M.; Halog, A. Consequential Life Cycle Assessment: A Review. Int. J. Life Cycle Assess. 2011, 16, 445-453. [CrossRef]

26. Ekvall, T.; Azapagic, A.; Finnveden, G.; Rydberg, T.; Weidema, B.P.; Zamagni, A. Attributional and Consequential LCA in the ILCD Handbook. Int. J. Life Cycle Assess. 2016, 21, 293-296. [CrossRef]

27. Finnveden, G.; Hauschild, M.Z.; Ekvall, T.; Guinée, J.; Heijungs, R.; Hellweg, S.; Koehler, A.; Pennington, D.; Suh, S. Recent Developments in Life Cycle Assessment. J. Environ. Manag. 2009, 91, 1-21. [CrossRef]

28. JRC-IES. ILCD Handbook: General Guide for Life Cycle Assessment-Detailed Guidance; Publications Office of the European Union: Luxembourg, 2010.

29. Plevin, R.J.; Delucchi, M.A.; Creutzig, F. Using Attributional Life Cycle Assessment to Estimate Climate-Change Mitigation Benefits Misleads Policy Makers. J. Ind. Ecol. 2014, 18, 73-83. [CrossRef]

30. Schuller, O.; Baitz, M.; Saint-Antonin, V.; Collet, P.; Sabathier, J. Attributional vs. Consequential LCA Methodology Overview, Review and Recommendations with Focus on Well-to-Tank and Well-to-Wheel Assessments; EUCar: Etterbeek, Belgium, 2020.

31. UNEP-SETAC. Global guidance principles for life cycle assessment databases-A basis for greener processes and products. In Shonan Guidance Principles; UNEP-SETAC: Paris, France, 2011.

32. Attribution-Definition of Attribution in English by Oxford Dictionaries. Available online: https://en.oxforddictionaries.com/ definition/attribution (accessed on 21 March 2019).

33. Plevin, R.J.; Delucchi, M.A.; Creutzig, F. Response to "On the Uncanny Capabilities of Consequential LCA" by Sangwon Suh and Yi Yang (Int. J. Life Cycle Assess., doi:10.1007/S11367-014-0739-9). Int. J. Life Cycle Assess. 2014, 19, 1559-1560. [CrossRef]

34. Rajagopal, D. A Step Towards a General Framework for Consequential Life Cycle Assessment. J. Ind. Ecol. 2017, $21,261-271$. [CrossRef] 
35. Sonnemann, G.; Vigon, B.; Baitz, M.; Frischknecht, R.; Krinke, S.; Suppen, N.; Weidema, B.; Wolf, M.-A. The context for global guidance principles for life cycle inventories. In Global Guidance Principles for Life Cycle Assessment Databases-A Basis for Greener Processes and Products_-"Shonan Guidance Principles"; UNEP-SETAC: Paris, France, 2011.

36. Schaubroeck, S.; Schaubroeck, T.; Baustert, P.; Gibon, T.; Benetto, E. When to Replace a Product to Decrease Environmental Impact? A Consequential LCA Framework and Case Study on Car Replacement. Int. J. Life Cycle Assess. 2020, 25, $1500-1521$. [CrossRef]

37. Brander, M.; Burritt, R.L.; Christ, K.L. Coupling Attributional and Consequential Life Cycle Assessment: A Matter of Social Responsibility. J. Clean. Prod. 2019, 215, 514-521. [CrossRef]

38. Cambridge English Dictionary PHYSICAL-Meaning in the Cambridge English Dictionary. Available online: https://dictionary. cambridge.org/dictionary/english/physical (accessed on 2 March 2020).

39. Hertwich, E. Understanding the Climate Mitigation Benefits of Product Systems: Comment on "Using Attributional Life Cycle Assessment to Estimate Climate-Change Mitigation ... . " J. Ind. Ecol. 2014, 18, 464-465. [CrossRef]

40. Mill, J.S. A System of Logic; Harper: Manhattan, NY, USA, 1843.

41. Holland, P.W. Statistics and Causal Inference. J. Am. Stat. Assoc. 1986, 81, 945-960. [CrossRef]

42. Weidema, B.; Grbeš, A.; Miguel, B. The implicit boundary conditions of attributional and consequential LCA. In Proceedings of the ISIE Conference 2015: Taking Stock of Industrial Ecology, Guildford, UK, 7-10 July 2015.

43. Ekvall, T.; Weidema, B.P. System Boundaries and Input Data in Consequential Life Cycle Inventory Analysis. Int. J. Life Cycle Assess. 2004, 9, 161-171. [CrossRef]

44. Baustert, P.; Schaubroeck, T.; Navarrete Gutiérrez, T.; Gibon, T.; Benetto, E. System boundaries in CLCA and the link with uncertainty-A case study on mobility policies in Luxembourg. In Proceedings of the 23nd SETAC Europe LCA Case Study Symposium, Barcelona, Spain, 27-28 November 2017.

45. Schaubroeck, T.; Baustert, P.; Igos, E.; Benetto, E. Is a Sustainability Assessment a Shot in the Dark? How to Deal with Its Nonquantified Uncertainty? Environ. Sci. Technol. 2020, 54, 2051-2053. [CrossRef] [PubMed]

46. Brandão, M.; Clift, R.; Cowie, A.; Greenhalgh, S. The Use of Life Cycle Assessment in the Support of Robust (Climate) Policy Making: Comment on "Using Attributional Life Cycle Assessment to Estimate Climate-Change Mitigation ... ". J. Ind. Ecol. 2014, 18, 461-463. [CrossRef]

47. Hellweg, S.; Hofstetter, T.B.; Hungerbuhler, K. Discounting and the Environment Should Current Impacts Be Weighted Differently than Impacts Harming Future Generations? Int. J. Life Cycle Assess. 2003, 8, 8. [CrossRef]

48. Levasseur, A.; Brandão, M.; Lesage, P.; Margni, M.; Pennington, D.; Clift, R.; Samson, R. Valuing Temporary Carbon Storage. Nat. Clim. Chang. 2011, 2, 6-8. [CrossRef]

49. Levasseur, A.; Lesage, P.; Margni, M.; Deschênes, L.; Samson, R. Considering Time in LCA: Dynamic LCA and Its Application to Global Warming Impact Assessments. Environ. Sci. Technol. 2010, 44, 3169-3174. [CrossRef]

50. Schaubroeck, T.; Rugani, B. A Revision of What Life Cycle Sustainability Assessment Should Entail: Towards Modeling the Net Impact on Human Well-Being. J. Ind. Ecol. 2017, 21, 1464-1477. [CrossRef]

51. Schrijvers, D.L.; Loubet, P.; Sonnemann, G. Developing a Systematic Framework for Consistent Allocation in LCA. Int. J. Life Cycle Assess. 2016, 1-18. [CrossRef]

52. Schrijvers, D.L.; Loubet, P.; Sonnemann, G. Critical Review of Guidelines against a Systematic Framework with Regard to Consistency on Allocation Procedures for Recycling in LCA. Int. J. Life Cycle Assess. 2016, 21, 994-1008. [CrossRef]

53. Weidema, B.P. In Search of a Consistent Solution to Allocation of Joint Production. J. Ind. Ecol. 2018, 22, 252-262. [CrossRef]

54. Weidema, B.P.; Bauer, C.; Hischier, R.; Mutel, C.; Nemecek, T.; Reinhard, J.; Vadenbo, C.; Wernet, G. Overview and Methodology: Data Quality Guidelines for the Ecoinvent Database Version 3; Ecoinvent Report 1 (v3); The Ecoinvent Centre: Zurich, Switzerland, 2013.

55. Wernet, G.; Bauer, C.; Steubing, B.; Reinhard, J.; Moreno-Ruiz, E.; Weidema, B. The Ecoinvent Database Version 3 (Part I): Overview and Methodology. Int. J. Life Cycle Assess. 2016, 21, 1218-1230. [CrossRef]

56. Schrijvers, D. Evaluation Environnementale Des Options de Recyclage Selon La Méthodologie D’analyse de Cycle de Vie: Établissement D'une Approche Cohérente Appliquée Aux Études de Cas de l'industrie Chimique. Ph.D. Thesis, Université de Bordeaux, Bordeaux, France, 2017.

57. Schrijvers, D.; Loubet, P.; Sonnemann, G. Archetypes of Goal and Scope Definitions for Consistent Allocation in LCA. Sustainability 2020, 12, 5587. [CrossRef]

58. Cardellini, G.; Mutel, C.L.; Vial, E.; Muys, B. Temporalis, a Generic Method and Tool for Dynamic Life Cycle Assessment. Sci. Total Environ. 2018, 645, 585-595. [CrossRef] [PubMed]

59. Collinge, W.O.; Landis, A.E.; Jones, A.K.; Schaefer, L.A.; Bilec, M.M. Dynamic Life Cycle Assessment: Framework and Application to an Institutional Building. Int. J. Life Cycle Assess. 2013, 18, 538-552. [CrossRef]

60. Pigné, Y.; Gutiérrez, T.N.; Gibon, T.; Schaubroeck, T.; Popovici, E.; Shimako, A.H.; Benetto, E.; Tiruta-Barna, L. A Tool to Operationalize Dynamic LCA, Including Time Differentiation on the Complete Background Database. Int. J. Life Cycle Assess. 2020, 25, 267-279. [CrossRef]

61. Tiruta-Barna, L.; Pigné, Y.; Navarrete Gutiérrez, T.; Benetto, E. Framework and Computational Tool for the Consideration of Time Dependency in Life Cycle Inventory: Proof of Concept. J. Clean. Prod. 2016, 116, 198-206. [CrossRef]

62. Soimakallio, S.; Brandão, M.; Ekvall, T.; Cowie, A.; Finnveden, G.; Erlandsson, M.; Koponen, K.; Karlsson, P.-E. On the Validity of Natural Regeneration in Determination of Land-Use Baseline. Int. J. Life Cycle Assess. 2016, 21, 448-450. [CrossRef] 
63. Koellner, T.; de Baan, L.; Beck, T.; Brandão, M.; Civit, B.; Margni, M.; Canals, L.M.I.; Saad, R.; de Souza, D.M.; Müller-Wenk, R. UNEP-SETAC Guideline on Global Land Use Impact Assessment on Biodiversity and Ecosystem Services in LCA. Int. J. Life Cycle Assess. 2013, 18, 1188-1202. [CrossRef]

64. Heijungs, R. Is Mainstream LCA Linear? Int. J. Life Cycle Assess. 2020, 25, 1872-1882. [CrossRef]

65. Suh, S.; Huppes, G. Methods for Life Cycle Inventory of a Product. J. Clean. Prod. 2005, 13, 687-697. [CrossRef]

66. Merciai, S. An Input-Output Model in a Balanced Multi-Layer Framework. Resour. Conserv. Recycl. 2019, 150, 104403. [CrossRef]

67. Merciai, S.; Schmidt, J. Methodology for the Construction of Global Multi-Regional Hybrid Supply and Use Tables for the EXIOBASE v3 Database. J. Ind. Ecol. 2018, 22, 516-531. [CrossRef]

68. Suh, S.; Weidema, B.; Schmidt, J.H.; Heijungs, R. Generalized Make and Use Framework for Allocation in Life Cycle Assessment. J. Ind. Ecol. 2010, 14, 335-353. [CrossRef]

69. Heijungs, R. Towards eco-efficiency with LCA's prevention principle: An epistemological foundation of LCA using axioms. In Product Innovation and Eco-Efficiency; Springer: Berlin/Heidelberg, Germany, 1998; pp. 175-185.

70. Müller, H.-G.; Wu, Y.; Yao, F. Continuously Additive Models for Nonlinear Functional Regression. Biometrika 2013, 100, 607-622. [CrossRef]

71. Ma, H.; Zhu, Z. Continuously Dynamic Additive Models for Functional Data. J. Multivar. Anal. 2016, 150, 1-13. [CrossRef]

72. Beck, N.; Jackman, S. Beyond Linearity by Default: Generalized Additive Models. Am. J. Polit. Sci. 1998, 42, 596-627. [CrossRef]

73. Biedermann, S.; Dette, H.; Woods, D.C. Optimal Design for Additive Partially Nonlinear Models. Biometrika 2011, 98, 449-458. [CrossRef]

74. Weidema, B.P.; Pizzol, M.; Schmidt, J.H.; Thoma, G. Social Responsibility Is Always Consequential-Rebuttal to Brander, Burritt and Christ (2019): Coupling Attributional and Consequential Life Cycle Assessment: A Matter of Social Responsibility. J. Clean. Prod. 2019. [CrossRef]

75. Arvesen, A.; Luderer, G.; Pehl, M.; Bodirsky, B.L.; Hertwich, E.G. Deriving Life Cycle Assessment Coefficients for Application in Integrated Assessment Modelling. Environ. Model. Softw. 2018, 99, 111-125. [CrossRef]

76. Marvuglia, A.; Benetto, E.; Rege, S.; Jury, C. Modelling Approaches for Consequential Life-Cycle Assessment (C-LCA) of Bioenergy: Critical Review and Proposed Framework for Biogas Production. Renew. Sustain. Energy Rev. 2013, 25, 768-781. [CrossRef]

77. Yang, Y.; Heijungs, R. On the Use of Different Models for Consequential Life Cycle Assessment. Int. J. Life Cycle Assess. 2017, 23, 751-758. [CrossRef]

78. Weidema, B.; Ekvall, T.; Heijungs, R. Guidelines for Applications of Deepened and Broadened LCA; Deliverable; LCA: Hendersonville, TN, USA, 2009.

79. Heimersson, S.; Svanström, M.; Ekvall, T. Opportunities of Consequential and Attributional Modelling in Life Cycle Assessment of Wastewater and Sludge Management. J. Clean. Prod. 2019, 222, 242-251. [CrossRef]

80. Schaubroeck, T.; Gibon, T.; Igos, E.; Benetto, E. Sustainability Assessment of Circular Economy over Time: Modelling of Finite and Variable Loops \& Impact Distribution among Related Products. Resour. Conserv. Recycl. 2021, 168, 105319. [CrossRef]

81. Majeau-Bettez, G.; Dandres, T.; Pauliuk, S.; Wood, R.; Hertwich, E.; Samson, R.; Strømman, A.H. Choice of Allocations and Constructs for Attributional or Consequential Life Cycle Assessment and Input-Output Analysis. J. Ind. Ecol. 2018, 22, 656-670. [CrossRef]

82. Weidema, B.P.; Schmidt, J.H. Avoiding Allocation in Life Cycle Assessment Revisited. J. Ind. Ecol. 2010, 14, 192-195. [CrossRef]

83. Majeau-Bettez, G.; Wood, R.; Strømman, A.H. Unified Theory of Allocations and Constructs in Life Cycle Assessment and Input-Output Analysis. J. Ind. Ecol. 2014, 18, 747-770. [CrossRef]

84. Schaubroeck, T.; Benetto, E. A need for a better characterisation of product benefit in life cycle sustainability assessment. In Proceedings of the SETAC Europe 28th Annual Meeting, Rome, Italy, 13 May 2018.

85. Cherubini, F.; Strømman, A.H.; Ulgiati, S. Influence of Allocation Methods on the Environmental Performance of Biorefinery Products-A Case Study. Resour. Conserv. Recycl. 2011, 55, 1070-1077. [CrossRef]

86. Wardenaar, T.; van Ruijven, T.; Beltran, A.M.; Vad, K.; Guinée, J.; Heijungs, R. Differences between LCA for Analysis and LCA for Policy: A Case Study on the Consequences of Allocation Choices in Bio-Energy Policies. Int. J. Life Cycle Assess. 2012, 17, 1059-1067. [CrossRef]

87. Weidema, B.P. Estimation of the Size of Error Introduced into Consequential Models by Using Attributional Background Datasets. Int. J. Life Cycle Assess. 2017, 22, 1241-1246. [CrossRef]

88. Moretti, C.; Corona, B.; Edwards, R.; Junginger, M.; Moro, A.; Rocco, M.; Shen, L. Reviewing ISO Compliant Multifunctionality Practices in Environmental Life Cycle Modeling. Energies 2020, 13, 3579. [CrossRef]

89. Atkinson, R. Atmospheric Chemistry of VOCs and NO

90. Heijungs, R.; Guinée, J.B.; Huppes, G.; Lankreijer, R.M.; Udo de Haes, H.A.; Wegener Sleeswijk, A.; Ansems, A.M.M.; Eggels, P.G.; van Duin, R.; de Goede, H.P.; et al. Environmental Life Cycle Assessment of Products: Guide and Backgrounds (Part 1); CML: Leiden, The Netherlands, 1992.

91. Cambridge English Dictionary Marginal. Available online: https://dictionary.cambridge.org/dictionary/english/marginal (accessed on 8 June 2021).

92. Wikipedia. Marginal Concepts; Wikipedia: San Francisco, CA, USA, 2020. 
93. Marginal-Definition of Marginal by Oxford Dictionary on Lexico.Com Also Meaning of Marginal. Available online: https:/ / www.lexico.com/definition/marginal (accessed on 14 June 2021).

94. Pizzol, M.; Scotti, M. Identifying Marginal Supplying Countries of Wood Products via Trade Network Analysis. Int. J. Life Cycle Assess. 2016, 22, 1146-1158. [CrossRef]

95. Sacchi, R. A Trade-Based Method for Modelling Supply Markets in Consequential LCA Exemplified with Portland Cement and Bananas. Int. J. Life Cycle Assess. 2018, 23, 1966-1980. [CrossRef]

96. Boulay, A.-M.; Benini, L.; Sala, S. Marginal and Non-Marginal Approaches in Characterization: How Context and Scale Affect the Selection of an Adequate Characterization Model. The AWARE Model Example. Int. J. Life Cycle Assess. 2019. [CrossRef]

97. Forin, S.; Berger, M.; Finkbeiner, M. Comment to “Marginal and Non-Marginal Approaches in Characterization: How Context and Scale Affect the Selection of an Adequate Characterization Factor: The AWARE Model Example". Int. J. Life Cycle Assess. 2020. [CrossRef]

98. Heijungs, R. The Average versus Marginal Debate in LCIA: Paradigm Regained. Int. J. Life Cycle Assess. 2021, 26, 22-25. [CrossRef]

99. De Meester, S.; Van der Vorst, G.; Van Langenhove, H.; Dewulf, J. Sustainability assessment methods and tools. In Management Principles of Sustainable Industrial Chemistry; Reniers, G.L.L., Sörensen, K., Vrancken, K., Eds.; Wiley-VCH Verlag GmbH \& Co. KGaA: Hoboken, NJ, USA, 2013; pp. 55-88. ISBN 978-3-527-64948-8.

100. Hauschild, M.Z.; Goedkoop, M.; Guinée, J.; Heijungs, R.; Huijbregts, M.; Jolliet, O.; Margni, M.; Schryver, A.D.; Humbert, S.; Laurent, A.; et al. Identifying Best Existing Practice for Characterization Modeling in Life Cycle Impact Assessment. Int. J. Life Cycle Assess. 2013, 18, 683-697. [CrossRef]

101. Swart, P.; Alvarenga, R.A.F.; Dewulf, J. Abiotic resource use. In Life Cycle Impact Assessment; Hauschild, M.Z., Huijbregts, M.A.J., Eds.; LCA Compendium-The Complete World of Life Cycle Assessment; Springer Netherlands: Dordrecht, The Netherlands, 2015; pp. 247-269. ISBN 978-94-017-9743-6.

102. JRC-IES. ILCD Handbook: Framework and Requirements for Life Cycle Impact Assessment Models and Indicators; Publications Office of the European Union: Luxembourg, 2010.

103. Niero, M.; Jensen, C.L.; Fratini, C.F.; Dorland, J.; Jørgensen, M.S.; Georg, S. Is Life Cycle Assessment Enough to Address Unintended Side Effects from Circular Economy Initiatives? J. Ind. Ecol. 2021, in press. [CrossRef]

104. Zimek, M.; Schober, A.; Mair, C.; Baumgartner, R.J.; Stern, T.; Füllsack, M. The Third Wave of LCA as the "Decade of Consolidation". Sustainability 2019, 11, 3283. [CrossRef]

105. Weidema, B.P.; Pizzol, M.; Schmidt, J.; Thoma, G. Attributional or Consequential Life Cycle Assessment: A Matter of Social Responsibility. J. Clean. Prod. 2018, 174, 305-314. [CrossRef]

106. Schaubroeck, T. The Concept of Cultural Ecosystem Services Should Not Be Abandoned. BioScience 2019. [CrossRef]

107. Guinée, J. Life cycle sustainability assessment: What is it and what are its challenges? In Taking Stock of Industrial Ecology; Clift, R., Druckman, A., Eds.; Springer International Publishing: Berlin/Heidelberg, Germany, 2016; pp. 45-68. ISBN 978-3-319-20570-0.

108. Klöpffer, W. Life Cycle Sustainability Assessment of Products. Int. J. Life Cycle Assess. 2008, 13, 89-95. [CrossRef]

109. Rödger, J.-M.; Kjær, L.L.; Pagoropoulos, A. Life cycle costing: An introduction. In Life Cycle Assessment: Theory and Practice; Hauschild, M.Z., Rosenbaum, R.K., Olsen, S.I., Eds.; Springer International Publishing: Cham, Switzerland, 2018 ; pp. 373-399. ISBN 978-3-319-56475-3.

110. Farinha, T. The contribution of terology for a sustainable future. In Proceedings of the 3rd WSEAS International Conference on Energy Planning, Energy Saving, Environmental Education, WSEAS, Canary Islands, Spain, 1-3 July 2009.

111. Heijungs, R.; Guinée, J. Some fundamentals on ALCA and CLCA. In EcoSD Annual Workshop: Consequential LCA; Presses des Mines: Paris, France, 2015; pp. 41-48. ISBN 978-2-35671-149-6. 